Review

\title{
An overview of polymeric dosage forms in buccal drug delivery: State of art, design of formulations and their in vivo performance evaluation
}

\author{
Bruno Fonseca-Santos*, Marlus Chorilli* \\ São Paulo State University (UNESP), School of Pharmaceutical Sciences, 14800-903 Araraquara, São Paulo, Brazil
}

\section{A R T I C L E I N F O}

\section{Keywords:}

Polymers

Buccal route

Pharmacokinetics

Pharmacodynamics

Drug delivery

Mucoadhesion

\begin{abstract}
A B S T R A C T
Owing to the ease of the administration, the oral cavity is an attractive site for the delivery of drugs. The main difficulty for administration via the buccal route is an effective physiological removal mechanism of the oral cavity that takes way the formulation from the buccal site and decreases the bioavailability of drugs. The use of mucoadhesive polymers in buccal drug delivery shows assessing buccal drug permeation and absorption, however some studies bring an in vivo performance. This review points to the use of polymers in the manufacture of drug delivery systems (hydrogels, films and tablets) and shows the results of their in vivo performance tests.
\end{abstract}

\section{Introduction}

Buccal route offers several advantages than oral route [1] due to the high total blood flow which ensures systemic bioavailability, avoiding firstpass hepatic metabolism and gastrointestinal drug degradation [2]. Moreover, it is easily accessible for administration by patient and suitable for dosage forms administration and removal. However, the accidental swallowing of delivery systems and the continuous dilution by saliva could determine a low residence time of formulation in buccal cavity and, consequently, a low drug bioavailability [3]. For this reason, various bio(muco) adhesive polymers which can establish a strong adhesive contact with the buccal mucosa, allowing one to increase residence time of delivery systems and to optimize drug bioavailability $[4,5]$.

Polymers have been related to drug delivery systems [6], especially buccal drug delivery [7-9]. Some structural characteristics for polymers include: strong hydrogen bonding groups, strong anionic or cationic charges, high molecular weight, chain flexibility, and surface energy properties favoring spreading on a mucus layer [10-12].

A wide range of polymers, both natural and synthetic, have been studied for their potential use as mucoadhesives (Table 1). The polymers that adhere to the mucin surface can be conveniently divided into three broad categories: 1) polymers that become sticky when placed in water and owe their bioadhesion to stickiness; 2) polymers that adhere through nonspecific, noncovalent interactions that are primarily electrostatic in nature (although hydrogen and hydrophobic bonding may be significant); 3) polymers that bind to specific receptor sites on the cell surface $[10,13,14]$.
For application to buccal mucosa, polymers may have desirable characteristics, such as: polymers and its degradation products should be nontoxic; it should not irritate the mucous membrane; the polymer should allow flexibility and comfort of the dosage form; it should adhere quickly to moist tissue and should possess some site specificity; and it should allow easy incorporation of the drug and offer no hindrance to its release $[12,15,16]$.

This review summarizes the applications of polymers for designing of dosage forms for buccal route, with emphasis on in vivo performance studies, which are pharmacological, pharmacodynamic and pharmacokinetic studies.

\section{Buccal drug delivery}

The release of drugs for the buccal route has gained great interest in Pharmacy and Materials Science [3,17]. This interest has increased because the oral route compared to oral administration, and it has more advantages and maximizes the therapeutic potential of drugs $[18,19]$. Drugs administered by the buccal route not show pre-systemic metabolism, however, it happens in the gastrointestinal tract, as well as the first pass metabolism in the liver after absorption to the bloodstream [18].

The main challenge for the success of buccal release is the residence time of the dosage forms in the oral environment. The dosage forms need to maintain contact with the mucous membrane to allow the drugs to act at the buccal site, or to be absorbed through the mucosa. However, the shearing in the oral environment, caused by saliva flow,

\footnotetext{
* Corresponding authors at: Universidade Estadual Paulista (UNESP), Faculdade de Ciências Farmacêuticas, Departamento de Fármacos e Medicamentos, Rodovia Araraquara-Jaú, 14801-902 Araraquara, São Paulo, Brazil.

E-mail addresses: bfonsecasantos@fcfar.unesp.br, fonsecasantos.bruno@gmail.com (B. Fonseca-Santos), chorilli@fcfar.unesp.br (M. Chorilli).
} 
Table 1

Mucoadhesive polymers in buccal delivery.

\begin{tabular}{|c|c|c|}
\hline Criteria & Categories & Examples \\
\hline \multirow[t]{6}{*}{ Source } & Semi-natural/natural & Agarose, chitosan, gelatin \\
\hline & & Hyaluronic acid \\
\hline & & Gums (guar, hakea, xanthan, gellan, carrageenan, pectin, and sodium alginate) \\
\hline & Synthetic & Cellulose derivatives: CMC, thiolated CMC, sodium CMC, HEC, HPC, HPMC, MC, methylhydroxyethylcellulose \\
\hline & & $\begin{array}{l}\text { Poly(acrylic acid)-based polymers: Carbomers, PAA, polyacrylates, poly(methylvinylether-co-methacrylic acid), poly(2- } \\
\text { hydroxyethyl methacrylate), poly(acrylic acid-co-ethylhexylacrylate), poly(methacrylate), poly(alkylcyanoacrylate), } \\
\text { poly(isohexylcyanoacrylate), poly(isobutylcyanoacrylate), copolymer of acrylic acid and PEG }\end{array}$ \\
\hline & & Others: Poly(N-2-hydroxypropyl methacrylamide) (PHPMAm), polyoxyethylene, PVA, PVP, thiolated polymers \\
\hline \multirow[t]{2}{*}{ Aqueous solubility } & Water-soluble & HEC, HPC (water $<38^{\circ} \mathrm{C}$ ), HPMC, PAA, sodium CMC, sodium alginate \\
\hline & Water-insoluble & Chitosan (soluble in dilute aqueous acids), EC \\
\hline \multirow[t]{3}{*}{ Charge } & Cationic & Aminodextran, chitosan, dimethylaminoethyl (DEAE)-dextran, trimethylated chitosan \\
\hline & Anionic & Chitosan-EDTA, CMC, pectin, PAA, sodium alginate, sodium CMC, xanthan gum \\
\hline & Non-ionic & Hydroxyethyl starch, HPC, poly(ethylene oxide), PVA, PVP, scleroglucan \\
\hline \multirow[t]{3}{*}{ Potential bioadhesive forces } & Covalent & Cyanoacrylate \\
\hline & Hydrogen bond & Acrylates [hydroxylated methacrylate, poly(methacrylic acid)], PC, PVA \\
\hline & Electrostatic interaction & Chitosan \\
\hline
\end{tabular}

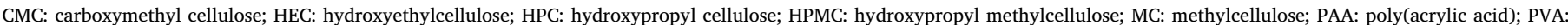
poly(vinyl alcohol); PVP: poly(vinyl pyrrolidone); EC: ethyl cellulose; PEG: polyethylene glycol; EDTA: ethylenediamine tetraacetic acid.

chew, swallow, speech, may prevent adhered to the oral mucosa and this leads to a reduction or no efficacy of drugs [18,20,21].

A buccal mucosa covers the inside of the cheek, as well as an area between gums and upper and lower lips [22] and has an average surface area of $100 \mathrm{~cm}^{2}$ [19]. Mucosa has a function to protect underlying tissues from mechanical and chemical damage [19].

The anatomy of the buccal site consists of three types of mucosa: the mucous membrane lining found outside the oral vestibule, the sublingual region and the specialized mucosa. The specialized mucosa is found on the dorsal surface of the tongue, while the masticatory mucosa is found on the hard palate and gums [21]. The mucous membrane lining comprises about $60 \%$, the masticatory mucosa approximately $25 \%$, and the specialized mucosa approximately $15 \%$ of the total surface area of the oral mucosa in an adult human [23]. Fig. 1 shows a schematic representation of oral cavity.

The masticatory mucosa is located in regions particularly sensitive to stress from chewing activity. The cells of the masticatory mucosa are keratinized and a lamina propria connects the mucosa to the periosteum. The mucous membrane lining, on the other hand, is not so subject to these masticatory shears and, consequently, has a non-keratinized epithelium, and a thin and elastic lamina attached to submucosa. The mucosa present in the dorsum of the tongue is a specialized mucosa and surfaces embedded with numerous papillae and taste receptors [23]. Schematic representation of oral mucosa histology is shown in Fig. 1.
The mucosa thicknesses range from 500 to $800 \mu \mathrm{m}$ for a buccal mucosa and for a sublingual and gingival mucosa, thickness values between 100 and $200 \mu \mathrm{m}$ [24]. The nature of the epithelial mucosa varies according to tissue function, but in general it functions as a barrier to lipophilic drugs [24]. Saliva is a moderately viscous aqueous fluid secreted by the parotid, submandibular and sublingual glands [25]. A salivary film is distributed over the mouth surfaces, coating the epithelial cells and tooth enamel [26] and the thickness of this film is about 70-100 $\mu \mathrm{m}$ [23].

The major components of saliva are mucus, proteins, minerals and enzymes. Saliva is considered a weak buffer system with a pH of 5.5-7, and the $\mathrm{pH}$ range depends on the composition and ionic composition that are affected by the type and degree of stimulation (smell, taste, and type of food). The normal salivary flow rate is approximately $0.5 \mathrm{~mL} \mathrm{~min}^{-1}$, resulting in daily secretion between 0.5 and $2 \mathrm{~L}$, but due to continuous swallowing, the constant volume of saliva in the mouth is approximately $1 \mathrm{~mL}[18,19]$.

Mucus is composed mainly of glycoproteins which are called mucins, which are macromolecules with a molecular weight between 0.5 and $20 \mathrm{MDa}$ [27]. Slomiany et al. [28] reviewed the molecular aspects of salivary mucins and the nature of oral mucosa interactions with mucin. The negative charges of the mucins, in physiological $\mathrm{pH}$ values, result of ionization of sialic acid and sulphate residues. These negative charges allow the mucin to attach to the surface of epithelial cells,

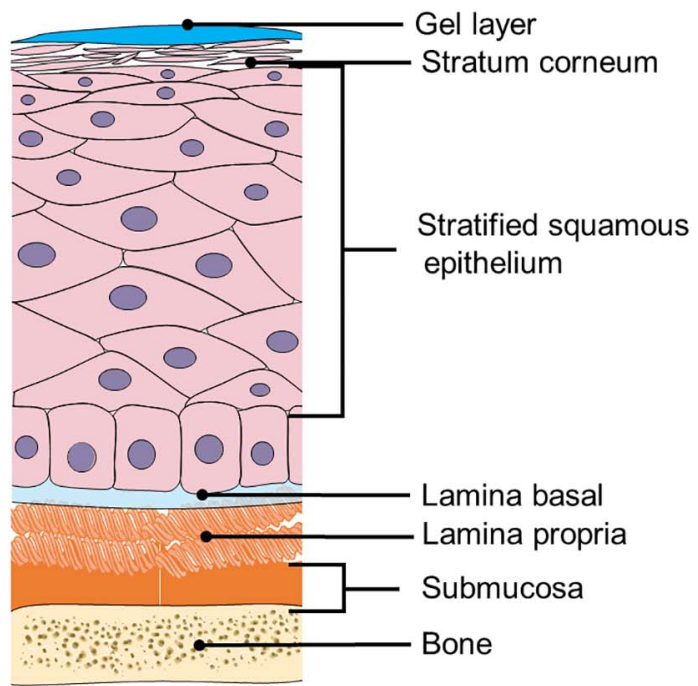

Gel layer Stratum corneum

Stratified squamous pithelium

Lower lip

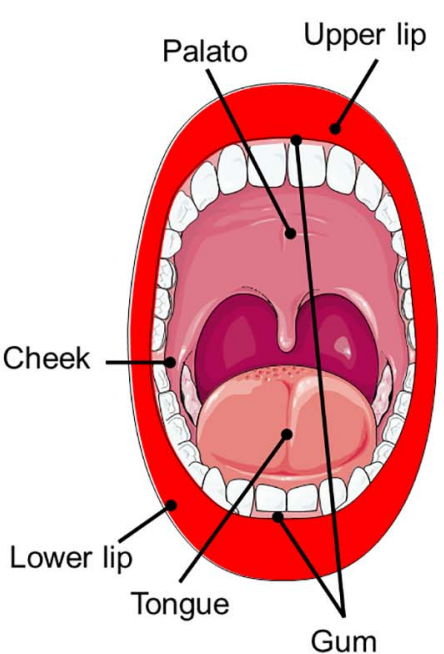

Fig. 1. Schematic representation of oral cavity and buccal mucosa histology. 
forming a gel layer on the surface of the epithelium. In aqueous media, the mucins molecules are complexed gelling systems and that are stabilized by intra- and intermolecular hydrogen bonding, electrostatic interactions and disulfide bonding between the cysteine residues present in non-glycosylated regions [29]. The amount of disulfide bond present in the mucins influences the their viscoelastic behavior [30].

Paderni et al. [31] reported that administration of drugs through the buccal mucosa can be subdivided into two different approaches that may result in a local or systemic effect. This variability results from the regional differences in terms of anatomical characteristics and permeability of each anatomical site [31,32]. The keratinized mucosae present in the gingival and hard palatal are not considered a site for systemic administration and are these mucosae is considered useful sites for the local delivery of drugs in the treatment of oral diseases located in the gingiva or palate $[31,33]$.

The administration through the non-keratinized mucosa can be subdivided into two approaches: sublingual delivery or delivery through the buccal mucosa [31]. The sublingual mucosa is more permeable and has high vascularization and thinner than the buccal mucosa, and it shows a viable site for rapid onset for the absorption of drugs [34]. Thus, the sublingual route is generally used for systemic delivery in the treatment of acute disorders (angina pectoris or acute pain). However, the surface of this mucosa is constantly washed by the saliva and the shear exerted by the tongue makes it difficult to maintain the dosage form in contact with the mucosa [34].

The cheeks mucosa is less permeable, and unable to provide a rapid onset of absorption when compared to the sublingual mucosa; however, it may have local or systemic effects when drugs are administered $[1,31]$. The surface of the buccal mucosa is relatively immobile and more permeable than the other tissues of the oral mucosa. Thus, it becomes a place of choice for the administration of controlled release systems that need to be adhered for an extended period [34].

Transport of drugs through the transcellular pathway, also known as the intracellular pathway, may occur by diffusion to low molecular weight molecules or by active transport, also known as facilitated diffusion, to polar or ionic compounds; or by endocytosis and transcytosis for macromolecules [35].

The transport of molecules through the intracellular pathway is a complex phenomenon that is dependent of physicochemical proprieties of the drugs, such as molecular weight, oil/water partition coefficient, ionic charge and structural conformation. Lipophilic compounds and small hydrophobic molecules predominantly pass through by intracellular transport [24]. These transport pathways are shown in Fig. 2.

Cell membrane is lipophilic, for hydrophilic drugs have difficulty to permeating the cell membrane. The passive transport of hydrophilic compounds, including macromolecules, such as peptides and proteins, may be enhanced by the interaction of the excipients of the formulation with the phospholipid bilayer and the integrated membrane proteins [35]. In the case of lipophilic drugs, the lipid bilayer performs the pathway and, for hydrophilic drugs, there is an interaction associated with the aqueous regions adjacent to the polar groups of the phospholipid head present in the lipid bilayers [36]. Water-soluble solutes, such as amino acids, ions and sugars, can be diffused through the pores present in cell membranes [35].

Although the buccal mucosa as a novel drug delivery route is being widely explored recently, its potential as a route for drug delivery was known to mankind centuries ago. Modern day researchers are therefore exploring the various routes available for drug delivery, especially through the oral mucosa, and coming up with novel drug delivery systems: tablets, films, patches, gels and nanotechnology-based systems (Table 2).

\section{Mucoadhesion theories}

Bioadhesion can be defined as the state in which two materials, at least one of which is biological, are held together for an extended period of time by interfacial forces $[17,85]$. Bioadhesive systems applied to mucous membranes are often defined as mucoadhesive, but the use of these terms may be interchangeable [86].

Mucoadhesive systems can be defined as those that bind the molecules of the mucus layer, but in reality it is difficult to discern whether the interaction occurs on the cell surface or between the molecules of the material and the mucus layer [87].

The mechanism of adhesion of certain molecules on the surface of a tissue or mucosa is not yet very well understood. The mucoadhesive pharmaceutical form should spread on the substrate to initiate a contact with the surface, promoting the diffusion of its chains into the mucus. The forces of attraction and repulsion arise, and for the occurrence of mucoadhesion, there must be a predominance of attraction forces [85].

Thus, the mucoadhesion process is generally divided into two stages, the contact the consolidation stage, both shown in Fig. 3. The first step is characterized by the contact between the material and the mucous membrane, where will occur the spreading and swelling of the formulation, initiating a contact with the mucus layer [88]. In the next step, in the consolidation phase, the mucoadhesive materials initiate a molecular interaction with the mucus by a van-der-Waals forces or hydrogen bonds [85].

There are two theories that explain the consolidation step: diffusion and dehydration theory. According to the theory of diffusion, mucoadhesive molecules and the mucus glycoproteins interact mutually by interpenetration of their chains and the supramolecular interactions [85]. This mechanism is shown in Fig. 4.

Diffusion theory tends to happen with the mucoadhesive device has characteristics that favor the interactions, both chemical and mechanical, with the mucus. Molecules with functional groups that can interact hydrogen bonds $(\mathrm{OH},-\mathrm{COOH})$, anionic surface charge; or flexible chains of polymers, can interact and penetrate the mucus layer [89]. The molecular structures of main polymers presented in this article are shown in Fig. 5.

Different individual adhesion theories have been suggested to explain mucoadhesion (Table 3), however the combination of these may provide a satisfactory understanding of the phenomena that have occurred $[90,91]$.

\section{Dosage forms for drug release}

\subsection{Hydrogels}

Hydrogels are three-dimensional, hydrophilic, polymeric homopolymers or copolymers networks capable of imbibing large amounts of water or biological fluids [92-94]. These hydrogels exhibit a thermodynamic compatibility with water which allows them to swell in aqueous media [92,95]. Hydrogels can be classified as neutral or ionic, based on the nature of the side groups of polymers. Hydrogels may also show a swelling behavior dependent on the external environment [96]; these systems are caller physiologically-responsive hydrogels [92,97] or recently as smart stimuli hydrogels [98-102]. In other words, polymeric formulations that are in sol forms before entering in the body, but change to gel forms under the physiological conditions [103,104]. Some of the factors affecting the swelling of physiologically-responsive hydrogels include $\mathrm{pH}$, ionic strength, temperature and electromagnetic radiation [105].

Porosity and mesh networks of hydrogels also permits loading of drugs into the gel matrix and subsequent drug release at a rate dependent on the diffusion coefficient of the small molecule or macromolecule through the gel network $[95,106,107]$. Hydrogels are also relatively deformable and can conform to the shape of the surface to which they are applied $[10,92,108]$. In the latter context, the muco- or bioadhesive properties of some hydrogels can be advantageous in immobilizing them at the site of application, i.e. buccal route [109] (Fig. 6). 


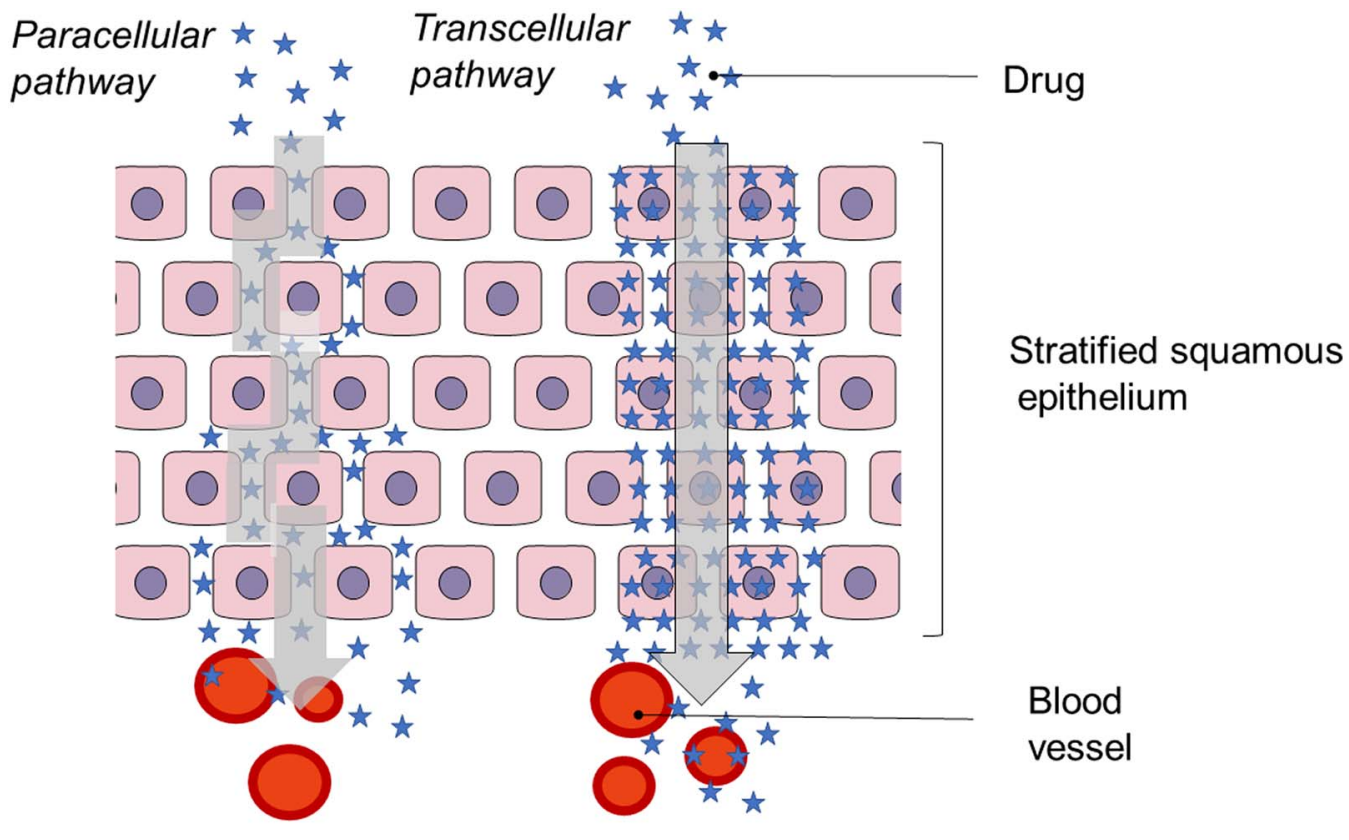

Fig. 2. The drug transport mechanism through the buccal mucosa involves two major routes: transcellular (intracellular) and paracellular (intercellular) pathways.
Chitosan gels were evaluated in dogs with periodontal disease to treatment of gingivitis. Gels containing doxycycline and meloxicam were applied in the mouth of Beagle dogs presenting gingivitis secondary to periodontal disease. The treatment was administered for seven days, every $12 \mathrm{~h}$ cycle. The results showed improvements in clinical score, but was not observed statistics significance between the groups [37].

Neonatal hypoglycaemia is a common condition affecting $5 \%$ to $15 \%$ of infants in the immediate postnatal period [110]. Dextrose gel can be administered by direct application to mucosal surfaces of the mouth, including buccal and lingual surfaces [38]. Absorption from these sites may allow rapid access to the circulation. Some proportion of the dose may be swallowed and absorbed from the gastrointestinal tract [111]. Major result showed the treatment with dextrose gel is inexpensive and simple to administer. This gel should be considered for first line treatment to manage hypoglycaemia in late preterm and term babies in the first $48 \mathrm{~h}$ after birth [38].

The peptide HsTX1[R14A] is a potent and selective blocker of the voltage-gated potassium channel, a well-recognized therapeutic target for autoimmune diseases [112]. To overcome the poorly oral absorption and consequent need for regular injections, the potential of the noninvasive buccal mucosa for systemic delivery was investigated. Then, this peptide in solution or formulated in chitosan gel with or without cetrimide was administered in Swiss mice. After buccal administration in mice, the peptide was detected in plasma, with the presence of cetrimide in the gel further enhancing plasma exposure, with area under the plasma concentration-time curve values of $77.9 \pm 9.7$ and $31.0 \pm 2.3 \mathrm{nM} \cdot \mathrm{h}^{-1}$, respectively [39]. This study enforces the buccal mucosa is a promising alternative administration route for the peptides for non-invasive routes. But, due to the physiochemical instability and enzymatic barrier of proteins and peptides there are several hurdle to develop suitable formulation [113-115]. Due the high molecular weight and size molecular is need of penetration enhancers, enzyme inhibitors and suitable vehicles for non-invasive delivery to increase the bioavailability [116].

Curcumin solid-lipid nanoparticle (SLN)-loaded gels composed by polycarbophil and poloxamer 407 and were tested for treatment of precancerous lesions [40]. Clinical study was performed in patients with oral erythroplakia. The samples were administered in the mouth at dose of $6 \mathrm{mg}$ for curcumin to day for 6 weeks. Clinical evaluations presented as pain index, and lesion size were made at study entry, every 2 weeks over a 6 -week period and 3 months after the study period. Polymeric binary mixture of both polymers provided mucoadhesive gel matrix of high mucoadhesion, high viscosity and good spreadability. In vivo residence time achieved a duration of $25 \mathrm{~min}$, this time allowed lipid nanoparticles penetration into the mucosal layer. Major results were higher rate of healing, effective pain index and reduction in lesion size of lesions with significant difference $(\mathrm{p}<0.05)$ to control gel (curcumin not entrapped into nanoparticles) [40]. The incorporation of curcumin-loaded SLN into mucoadhesive gel provided an efficient approach for oral mucosal targeting.

Another study shows a Carbopol ${ }^{\circledR}$ gel for incorporation of simvastatin-loaded microemulsion for buccal delivery [41]. Pharmacokinetics study was performed in Albino Wistar rats and showed a maximum concentration (Cmax) value $\left(131.208 \pm 21.563 \mathrm{ng} \mathrm{mL}^{-1}\right)$ of the buccoadhesive gel was found to be significantly higher $(p<0.001)$ when compared to the same dose administered by an oral route (Cmax$68.513 \pm 9.821 \mathrm{ng} \mathrm{mL}^{-1}$ ). The relative bioavailability (Fr) of the optimized buccal gel was about $385.3 \%$ higher than that of the oral marketed tablet [41].

Graciano et al. [42] reported toluidine blue O-loaded chitosan gels as a delivery system for photodynamic therapy of buccal cancer. In vivo retention of mucosa and photodynamic therapy were evaluated in Swiss mice. Animals were treated with the formulation at exposure times $(1 \mathrm{~h}$, $3 \mathrm{~h}$ or $6 \mathrm{~h}$ ). These results showed that the $4 \%$ chitosan gel enhanced photosensibilizer retention by approximately 1.9 -fold relative to the control (toluidine blue $\mathrm{O}$ in solution) ( $\mathrm{p}<0.001$ ). Photodynamic therapy was evaluated by application of formulation in the tongue and $1 \mathrm{~h}$ after administration, the site was irradiated by a laser operating at $670 \mathrm{~nm}$ at a total energy of $80 \mathrm{~J} / \mathrm{cm}^{2}$. The results showed an increase in the number of apoptotic cells when treated with $4 \%$ chitosan gel containing $1 \%$ toluidine blue $\mathrm{O}$ followed by laser exposure. This increase was approximately 1.8 fold greater and was significantly different from the controls $(\mathrm{p}<0.001)$ [42].

Jin et al. [43] investigated the potential of the buccal mucosa of Stichodactyla helianthus neurotoxin-loaded chitosan gel. This peptide is used for the treatment of autoimmune diseases. Formulations were administered in the buccal mucosa of mice and the pharmacokinetics was evaluated. Concentration of neurotoxin was achieved at the initial $2 \mathrm{~h}$ post-administration. Cmax was $\sim 16 \mathrm{nM}$ and $\sim 2 \mathrm{nM}$ for neurotoxin- 


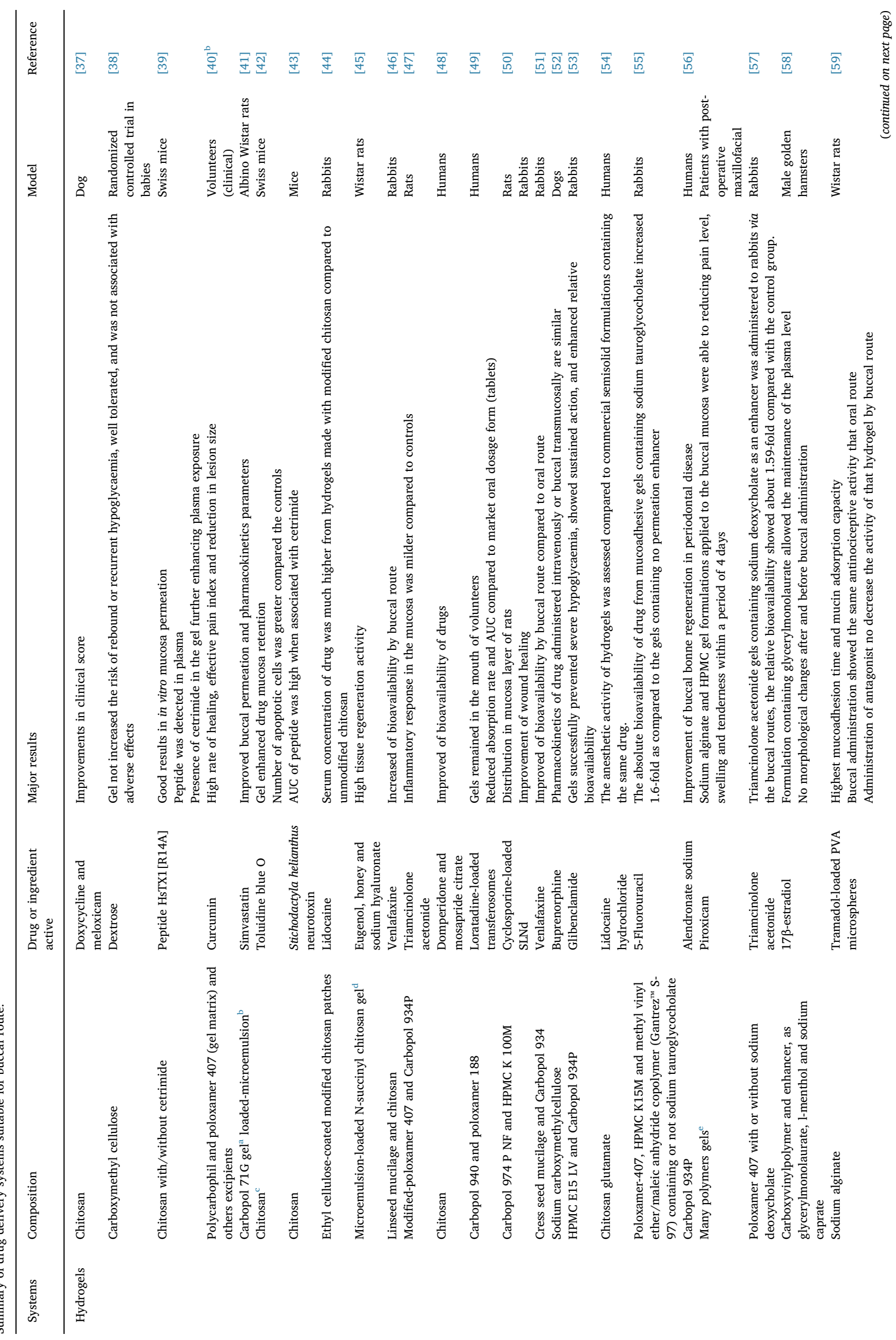




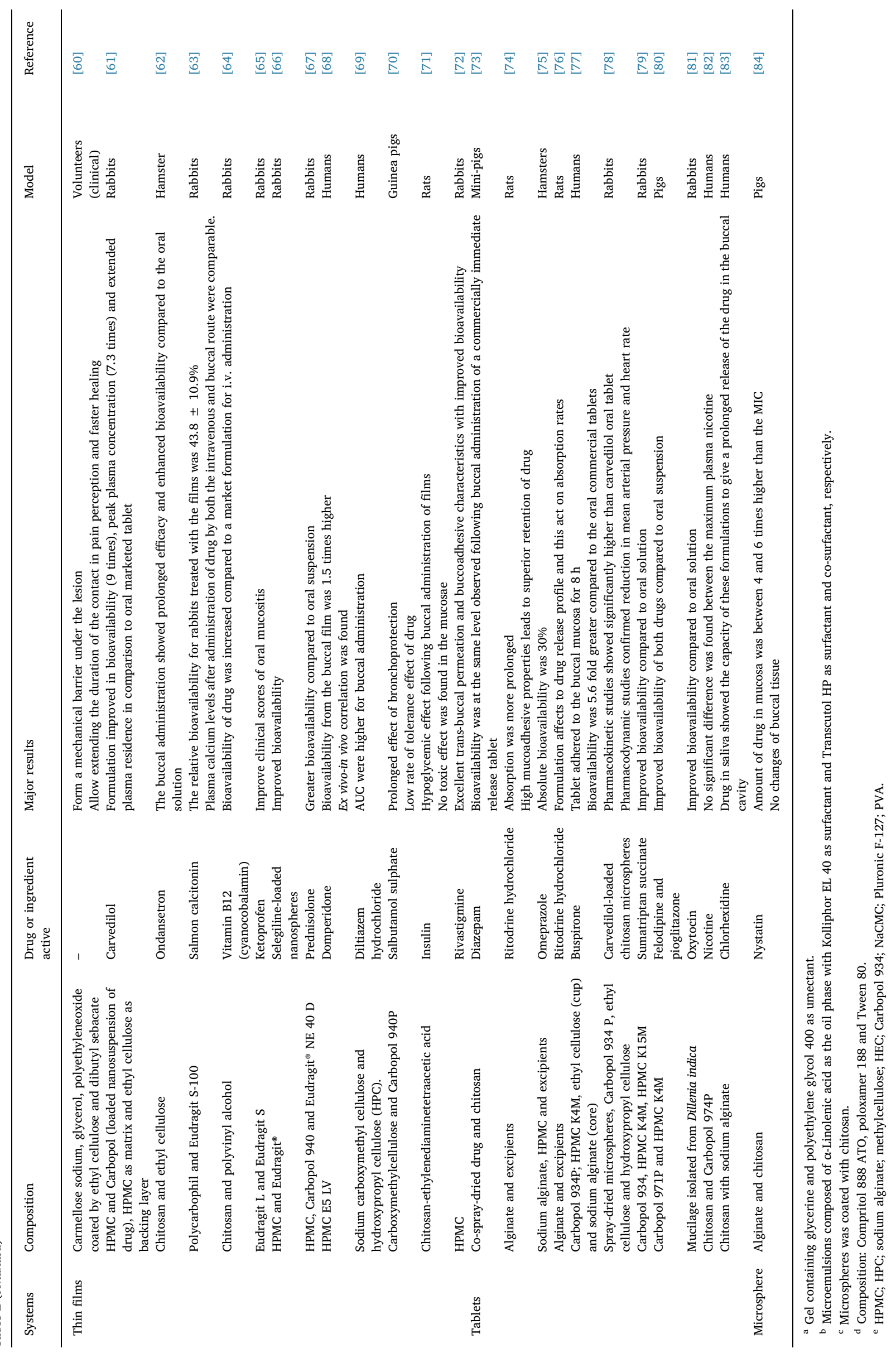




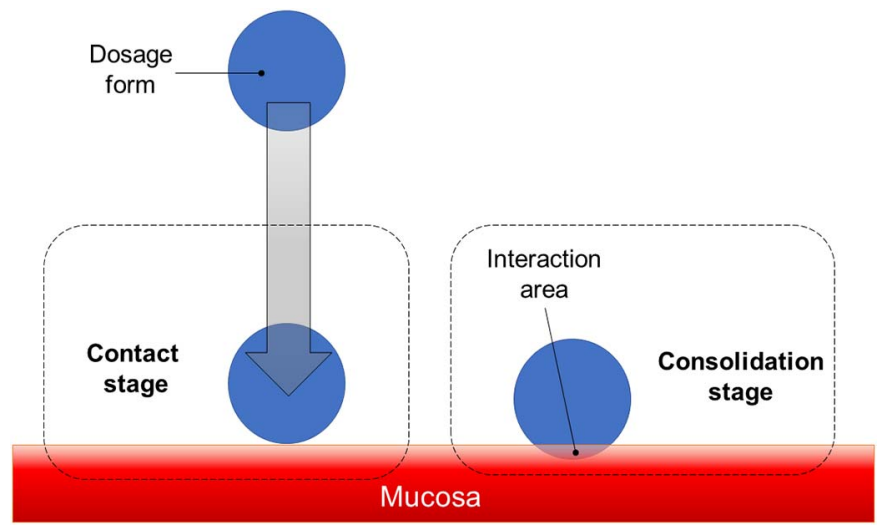

Fig. 3. The two stages in mucoadhesion.

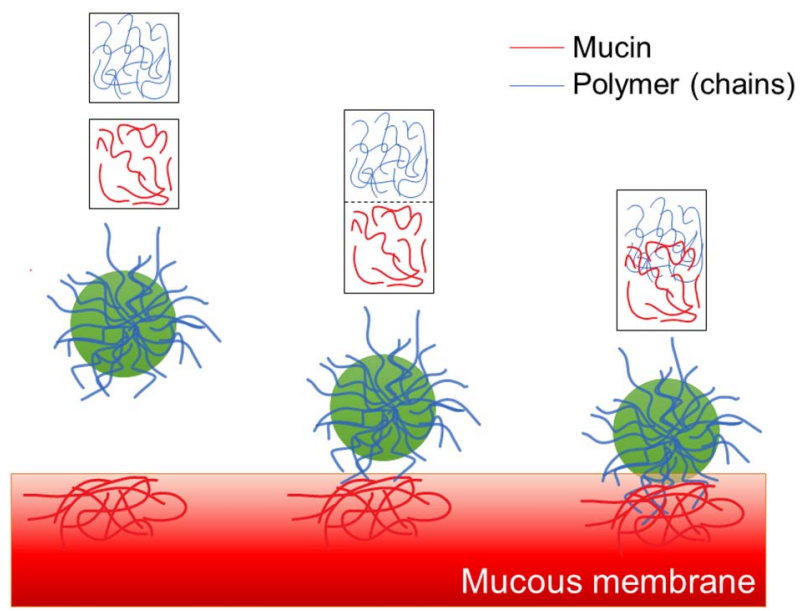

Fig. 4. Secondary interactions resulting from interdiffusion of bioadhesive polymer chains and mucins of mucus.

loaded gel containing cetrimide and -loaded gel without cetrimide, respectively, and AUC values of $55.8 \pm 6.3 \mathrm{nM} \cdot \mathrm{h}$ and $22.9 \pm 4.9 \mathrm{nM} \cdot \mathrm{h}$ in the presence and absence of cetrimide, respectively [43]. Among these chemicals, like cetrimide, used for the drug permeation enhancement in the buccal route [32].

A catechol-modified chitosan crosslinked with genipin patches were developed [44]. In-vivo studies concluded these systems adhere to rabbit buccal mucosa. Due this mucoadhesive force, lidocaine, as drug model, was detected in the serum of rabbits. Howeever, the serum content for modified chitosan was much higher than unmodified chitosan as matrix material. These systems show no inflammation on the buccal tissue in contact with the patches. These systems show that the proposed catechol-modified chitosan hydrogel is a promising mucoadhesive and biocompatible hydrogel system for buccal drug delivery [44].

A microemulsion was loaded into $\mathrm{N}$-succinyl chitosan gel and this system was tested in 5-fluoro uracil induced oral mucositis in mice. The results showed enhanced survival ratio, weight gain and high tissue regeneration activity than chitosan gel formulation within 15 days [45].

Linseed mucilage based gel was loaded venlafaxine with propose to avoid first pass metabolism, which leads to increase the bioavailability of the drug [46]. Designed formulation was tested in rabbits and the bioavailability by the oral route and buccal route were compared with that of the intravenous route. Results showed values of $63.08 \pm 1.28 \%$ by buccal route, which was higher than by the oral route $(39.21 \pm 6.18 \%)$. Based on these results, the combination of linseed mucilage and chitosan can be used to form a buccal mucoadhesive gel and increased the bioavailability of venlafaxine [46].
Triamcinolone acetonide-loaded hydrogel (composed by poloxamer and carbopol) was prepared by electron beam irradiation and evaluated for use as a buccal mucoadhesive drug delivery system [47]. Topical therapeutic effect of triamcinolone acetonide on wounded rat buccal mucosa was performed. Histological studies of tissue showed the inflammatory response in the mucosa was milder than that in the other groups (saline and drug solution), and the wound surface was completely covered with hyperkeratotic epithelial cells [47].

Elkomy et al. [49] to develop transferosomal gel for transbuccal delivery of loratadine due limited solubility, poor oral bioavailability of this drug. Drug loaded-transferosome was incorporated into Carbopol ${ }^{\circledR}$ and Poloxamer ${ }^{\circledast}$ gels. The systems were evaluated in humans and the parameters pharmacokinetics were achieved. Results showed the bioavailability of the transferosomal gel when compared to marketed oral obtained reduced values for Cmax and AUC and bioavailability was 76 and $90 \%$, respectively, when the buccal gel was used. The presence of gel remainders in the buccal cavity of all volunteers after $120 \mathrm{~min}$ of the administration.

Karavana et al. [50] designed a Cyclosporine A-loaded SLN and its was incorporated into Carbopol 974 P NF and HPMC K 100M for formation of hydrogels. In vivo distribution of gels was performed and formulations were applied on the rat buccal mucosa. Besides, the efficacy was evaluated by oral ulcer model on the gingiva in the New Zealand rabbits. In vivo distribution studies showed that the formulations containing nanocarriers remained on the buccal mucosa $6 \mathrm{~h}$ after application. Lesions were covered with the gel formulation containing no active agent; moderate improvement was observed, compared with untreated animals, suggesting that the gel base provided a protective layer over the lesion. At end of treatment, histological studies showed epithelialization in both treatment groups while incomplete epithelialization was observed in the control group [50].

Pharmacokinetics of buprenorphine in a sodium carboxymethylcellulose gel administered to buccal route was compared to same drug administered by intravenous route in dogs [52]. AUC were found and was $3082 \pm 1047$ and $6032 \pm 1884 \mathrm{ng} \mathrm{min} \mathrm{mL}^{-1}$ and absolute bioavailability was $63 \%$. These results suggest that the pharmacokinetics of drug administered intravenously or transmucosally are similar and that transmucosal administration may be considered as a noninvasive alternative to intravenous administration [52].

HPMC E15 LV and Carbopol 934P blended gels were developed for achieving enhanced bioavailability of glibenclamide [53]. In-vivo evaluation for pharmacodynamic and pharmacokinetic properties of the optimized gel was done in rabbits. Major results showed the reduction in blood glucose levels of buccal gels in comparison with oral suspension of the tablet of glibenclamide in rabbits was significant $(\mathrm{p}<0.05)$ between the glibenclamide marketed tablet and the formulated buccal gels up to the $10 \mathrm{~h}$ and $(\mathrm{p}<0.01)$ in the $24 \mathrm{~h}$. The decrease in blood glucose levels up to $19.14 \pm 2.41 \%$ in the case of normal rabbits, and $35.45 \pm 0.97 \%$ in the case of diabetic rabbits. The pharmacokinetic parameters obtained with gels were significantly $(\mathrm{p}<0.05)$ different from those obtained with tablet administration, which could be due to the rapid absorption of drugs via the oral route; whereas drug in the buccal route were slowly but continuously absorbed. $\mathrm{AUC}_{0-\infty}$ $\left(\mathrm{h} \mu \mathrm{g} \mathrm{mL}{ }^{-1}\right)$ was $108.46 \pm 1.78$ and $237.61 \pm 4.30$ for glibenclamide oral suspension of tablet and gel formulation, respectively [53].

Chitosan glutamate gels were investigated for local anesthetic activity for buccal application [54]. The pharmacological activity of the lidocaine-loaded hydrogels was assessed in healthy volunteers. All the tested hydrogels produced a mean local anesthetic activity lasting 20-30 min and was not statistically different $(\mathrm{F}>0.1)$ from the results obtained with the commercial product $(\approx 19 \mathrm{~min})$. The highly significant differences in the activity measured among the hydrogels (in presence of glycerin) had a strong effect on the technological properties of these formulations [54].

Hydrogels of Poloxamer-407, HPMC K15M and methyl vinyl ether/ 
<smiles>CCOC1C(CO)OC(CC)[C@H](N)C1O</smiles>

Chitosan<smiles>CCC(C)C(=O)O</smiles>

Poly (acrylic acid)*<smiles>CCCCCCCC</smiles>

Alginate

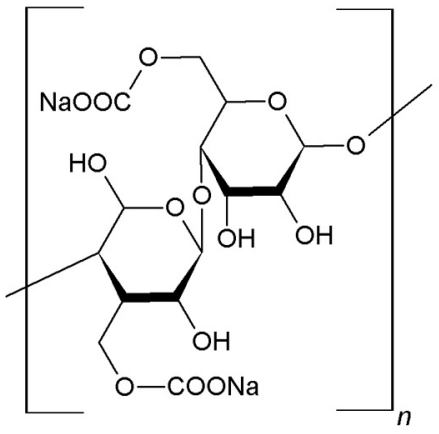

Carboxymethyl cellulose<smiles>CC(C)OC(=O)CC(C)OCCO</smiles>

Poloxamer

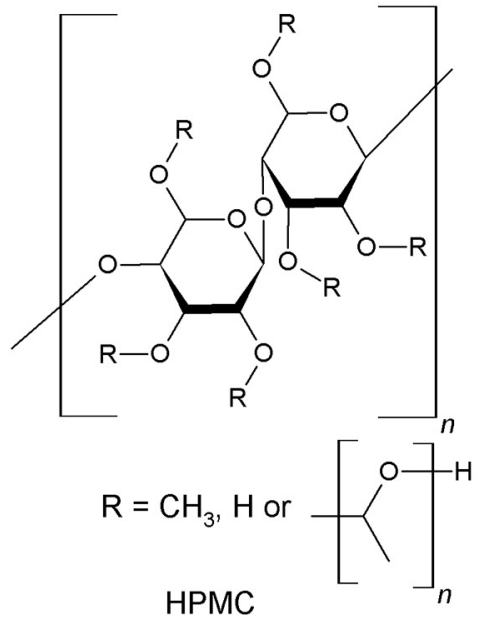<smiles>CCOCC1O[C@H](OCC)[C@H](O)[C@H](O)[C@H]1COCC</smiles>

Ethyl cellulose

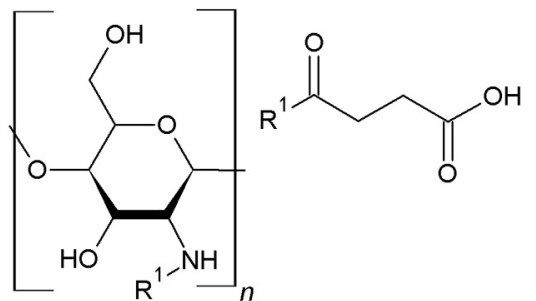

$\mathrm{N}$-succinyl-chitosan

Fig. 5. Chemical structures of main polymers presented in this review.

maleic anhydride copolymer (Gantrez ${ }^{\mathrm{TM}}$ S-97) and these hydrogels were loaded with5-fluorouracil (5-FU) [55]. For residence time and mucoadhesion the gels were radiolabeled and then were applied in buccal mucosa of rabbits. Gel formulations were place in the buccal cavity, the rabbits were fixed on a board and imaging was performed using a single photon emission computerized tomography gamma camera [55]. The $\gamma$ scintigraphic images of the rabbits taken after $6 \mathrm{U}$ ) h post-administration of buccoadhesive gels showed the presence of major portion of gels in the buccal cavity indicating in vivo bioadhesion of the gels. For pharmacokinetics from oral tablets, gels and intravenous administration were achieved. AUC was $6562.73 \pm 854,7069 \pm 902$,
$7787.99 \pm 1054$ and $12,653.65 \pm 140521,467.79 \pm 1701.12$ for oral conventional tablet, oral solution, gel without STGC (control), gel with sodium tauroglycocholate and intravenous administration, respectively. The absolute bioavailability was $32.16 \%$ for oral conventional tablet, $32.92 \%$ for oral solution, $36.28 \%$ for gel without sodium tauroglycocholate, $58.52 \%$ for gel with sodium tauroglycocholate, and $100 \%$ for intravenous administration. Thus, the buccal absorption of 5FU from the gel containing sodium tauroglycocholate as an enhancer was significantly higher $(\mathrm{p}<0.05)$ than that from the gel without enhancer [55].

Venlafaxine-loaded cress seed mucilage based gel reinforced with

Table 3

Theories used to explain the adhesive interactions between mucoadhesive materials and mucus/mucosa

\begin{tabular}{|c|c|}
\hline Theory & Summary \\
\hline Electronic theory & Adhesion is established because of the electrostatic attraction between negatively charged mucin and positively charged materials \\
\hline Adsorption theory & Adhesive interactions are related to the establishment of hydrogen and van-der-Waals bonds and chemisorption \\
\hline Wetting theory & Adhesion is related to the ability of a mucoadhesive (when in liquid form) to spread through the mucus layer \\
\hline Diffusion theory & $\begin{array}{l}\text { Adhesion is established by the interpenetration of macromolecular (polymeric or other) mucoadhesives with mucin fibers, driven by a concentration } \\
\text { gradient differential }\end{array}$ \\
\hline Fracture theory & Adhesion is the necessary force for the interfacial detachment of two solid surfaces previously attached \\
\hline Mechanical theory & Adhesion depends on the roughness of two different surfaces and the area available for interaction \\
\hline
\end{tabular}

Note: Adapted to table from Smart [85]. 


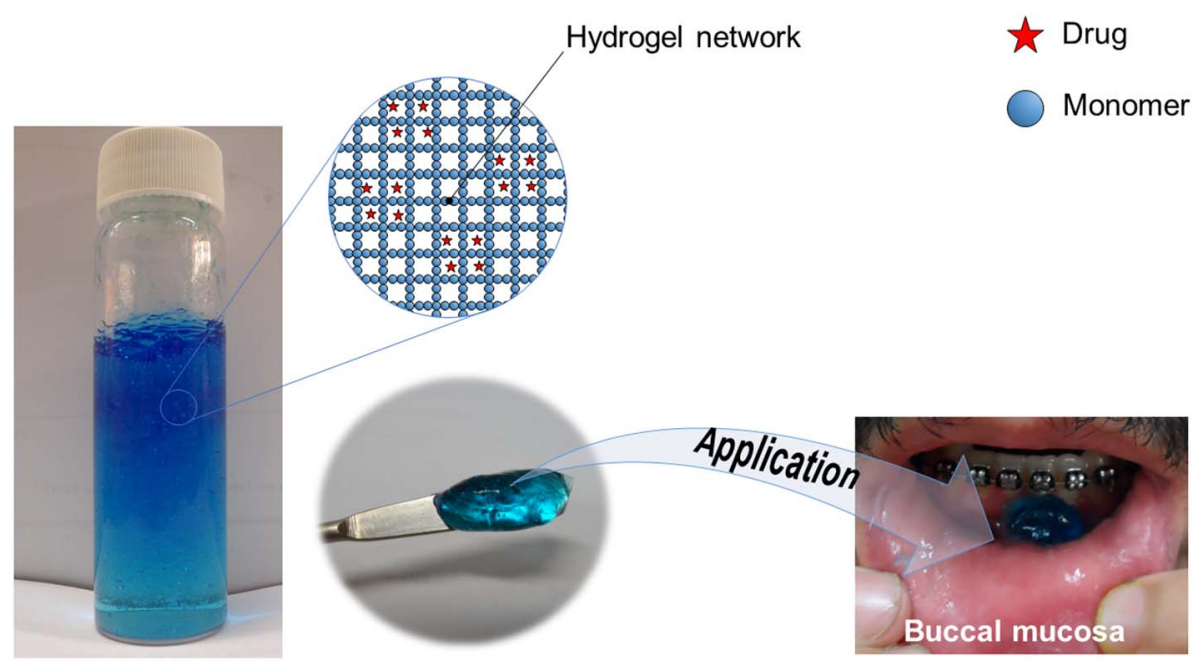

Fig. 6. Carbopol ${ }^{\circledast} 940$ hydrogel and its application on surface of buccal mucosa. Enlarged area shows network and the drug entrapped in the mesh. Gel was colored with methylene blue dye for a better visualization. (For interpretation of the references to color in this figure legend, the reader is referred to the web version of this article.)
Carbopol 934 was developed and the formulation was analyzed for pharmacokinetic parameters in rabbits. Gel-based formulation showed the Cmax of $24.19 \pm 0.72 \mathrm{ng} \mathrm{mL}^{-1}$ by buccal route of administration and $17.98 \pm 1.15 \mathrm{ng} \mathrm{mL}^{-1}$ by oral route of administration. This study concludes the bioavailability of gel-based by buccal route was $54.44 \%$ and that of by oral route was $39.60 \%$ [51].

Carbopol 934P gel was loaded alendronate sodium and its was evaluated for the treatment of bone resorptive lesions in periodontitis. In vivo studies were carried out for 6 months in patients and revealed a potent inhibition effect on bone resorption by inhibition of osteoclasts. Moreover, there was an increase in bone formation, gingival index, probing pocket depth, and gain attachment level [56].

Several buccal gel formulations containing piroxicam were prepared and evaluated [117]. For clinical studies, sodium alginate and HPMC gel formulations applied to the buccal mucosa of patients were better than or equally effective to the orally administered commercial product in reducing pain level, swelling and tenderness within a period of 4 days [117].

Acetonide-loaded poloxamer 407 gels were prepared and the in vivo performance were evaluated by pharmacokinetics studies and histological examination after buccal administration of formulations [57]. Formulations hydrogels was or not incorporated sodium deoxycholate, as enhancer of penetration. Absolute bioavailability to IV (\%) was 30.1 for hydrogel without enhancer and $\mathbf{4 7 . 9}$ for hydrogel with enhancer. The buccal mucosa treated with an enhancer group showed that the number of Paneth cell was a little increased. No globular and cellular changes between the normal and enhancer group was found [57].

Carboxyvinylpolymer hydrogels and enhancer, as glycerylmonolaurate, L-menthol and sodium caprate was loaded $17 \beta$-estradiol [58]. The buccal administration of $17 \beta$-estradiol in the $40 \%(w / w)$ ethanol hydrogels containing $2 \%(\mathrm{w} / \mathrm{w})$ glycerylmonolaurate allowed the maintenance of the plasma level at above $300 \mathrm{ng} / \mathrm{mL} \mathrm{cm}^{2}$ for $7 \mathrm{~h}$ after application in hamster. Morphological changes of the mucosa were examined by SEM at $7 \mathrm{~h}$, and shows no visible change compared with before application of the ethanol gel [58].

Tramadol microspheres-loaded hydrogel with adequate bioadhesion and providing controlled drug release for buccal delivery [59]. PVA microspheres were prepared by ionic gelation and extrusion method. These microspheres were dispersed into gel of CMC, HEC, or HPMC at $2.5 \%$ and Carbopol $^{\circledast} 940$ at $1 \%$. All formulations were tested and formulation containing alginate attained the strongest interaction with mucin; this may be also because of the intrinsic bioadhesive properties of alginate. This same formulation attained the highest permeation, and complete drug permeation was achieved during $6 \mathrm{~h}$. In vivo antinociceptive was evaluated on Wistar rats and performed using the hot plate method. The AUC was found $291.14 \pm 19.10$, 307.42 \pm 20.13 and $6.68 \pm 0.91$ for microspheres-loaded hydrogel by buccal route, solution of drug administered by oral route and control group, respectively. The maximum analgesic effect was valued $66.51 \pm 7.01$, $76.50 \pm 5.91$ and $5.85 \pm 0.41$ for oral route and control group, respectively. Hydrogel treatment was nonsignificant $(\mathrm{p}>0.05$ ) when compared to oral route. However, when the antagonist $\mathrm{N}$ was administered following the formulations, the AUC value was $63.29 \pm 6.12$ to oral administration of drug and was $261.23 \pm 26.71$ for microspheres-loaded hydrogel by buccal route, and maximum analgesic effect were $22.66 \pm 3.31$ and $62.24 \pm 6.21$ to drug by oral route and formulation test, respectively. Oral administration attained only about $20 \%$ of effect for oral administration and antagonist, while there was no significant difference between microspheres-loaded hydrogel by buccal route and the same treatment plus antagonist. This suggests bypassing the first-pass effect, the formation of this metabolite is partially inhibited; therefore, the buccal route can arguably provide an alternative safer route of administration decreasing dependence, abuse, and tolerance effect of the drug [59].

\subsection{Thin films}

Mucoadhesive buccal films are retentive dosage forms that release the drug directly into the biological substrate. These films are thin and releases topical drugs in the oral cavity at a slow and predetermined rate, provide discrete advantages over traditional dosage forms for treatment of many diseases [118].

Daněk et al. [60] designed flexible films for use in aphthous lesions of the oral cavity. The clinical study was performed on 36 volunteers suffering from aphthous lesions. The first group was treated with oral gel containing cholin and the second group was treated with the same preparation and the lesion was covered with a mucoadhesive film. All formulations were applied three times a day for 10 days. The results showed the application of buccal films covering aphthous lesions during the treatment significantly increased the rate of healing when compared with the application of gel alone. Furthermore, the pain improvement was statistically at day 3 for experimental group and at day 10 for control group. The use this system represents a promising to the mechanical barrier effect and allows extending the duration of the contact between the applied treatment agent, like a gel dosage form, and the lesion, resulting in the reduction in pain perception and faster healing of the lesion.

Buccal films containing three layers (mucoadhesive layer, drug nanosuspension containing layer and backing membrane) was designed [61]. Nanosuspension was incorporated into HPMC and Carbopol 934P layer. First layer was formed by HPMC and backing membrane was composed by ethyl cellulose. In vivo studies were carried out in the 
rabbit to compare the absorption of carvedilol from formulation film through buccal route compared with marketed oral tablets. Pharmacokinetics parameters like Cmax of formulation (356.91 $\pm 29.5 \mathrm{ng} \mathrm{mL}^{-1}$ ) were 7.3 times higher than that of oral tablet $\left(48.73 \pm 14.1 \mathrm{ng} \mathrm{mL}^{-1}\right)$. Time maxima (Tmax) of drugs was $4 \mathrm{~h}$ and $2 \mathrm{~h}$ for formulation and oral marketed tablet, respectively. AUC (ng h mL ${ }^{-1}$ ) was $4154.37 \pm 80.22$ for nanosuspension incorporated mucoadhesive buccal film and $1813.70 \pm 42.53$ for commercial tablets, and relative bioavailability was $916 \%$. It was concluded to develop suitable systems for buccal delivery of carvedilol with excellent improvement in bioavailability [61].

Sayed et al. [48] investigated the efficiency of buccal gel dosage forms to deliver poor orally absorbed drugs compared to marketed tablets of domperidone and mosapride citrate. Chitosan gel formulations achieved relative bioavailability compared to the market products, where buccal gel of domperidone and mosapride citrate achieved relative bioavailability of $202 \%$ and $162 \%$, respectively [48]. The buccal mucosa has a rich blood supply and it is relatively permeable, this may favor the absorption of drugs [3].

Park et al. [62] developed ondansetron-loaded chitosan thin films and impermeable backing layer was made from ethyl cellulose, ethanol and castor oil. In vivo study was performed in hamsters. Ondansetronloaded films were applied to buccal mucosa of the hamsters and ondansetron in solution was administered by oral administration. The AUC from time 0 to $24 \mathrm{~h}\left(\mathrm{AUC}_{0-24 \mathrm{~h}}\right)$ and pharmacokinetics parameters were obtained. From oral solution and buccal films, Cmax was $40.5 \pm 9.2$ and $41.4 \pm 3.5 \mathrm{ng} \mathrm{mL}^{-1}$, Tmax was $1.1 \pm 0.1$ and $1.3 \pm 0.14 \mathrm{~h}$, AUC was $156.5 \pm 49.5$ and $319.0 \pm 8.8 \mathrm{~h} \mathrm{ng} \mathrm{mL}^{-1}$ $(\mathrm{p}<0.05)$ and $\mathrm{t}_{1 / 2}$ was $12.6 \pm 2.7$ and $21.1 \pm 4.9 \mathrm{~h}(\mathrm{p}<0.05)$, respectively.

Salmon calcitonin was formulated into layer composed by Polycarbophil ${ }^{\circledast}$ and Eudragit S-100 [63]. This film layer was coated with wax (DENTSPLY ${ }^{\circledR}$ Utility Wax). Plasma studies were performed in New Zealand White Rabbits. The relative bioavailability of calcitonin in rabbits treated with patch was $43.8 \pm 10.9 \%$. However, the reductions in plasma calcium levels after administration of calcitonin by intravenous and buccal route were comparable [63]. This study shows calcitonin was effectively delivered therapeutically efficacious amounts across the buccal mucosa in rabbits.

Chitosan and polyvinyl alcohol films were designed and loaded with Vitamin B12. In vivo study was performed and AUC showed 1.5-fold increases in the bioavailability of cyanocobalamin compared with the marketed I.M. injection [64]. This finding shows a noninvasive formulation for buccal delivery of drugs.

Reda et al. [65] developed ketoprofen-loaded Eudragit L and Eudragit $S$ nanofibers by the electrospinning technique; and a selected formulation was evaluated in vivo on induced oral mucositis in rabbits. Major results show reduced clinical severity of mucositis in rabbits under the current experimental conditions. Moreover, ex vivo permeation study revealed that only a small fraction of drug permeated from this formulation.

HPMC and Eudragit films were developed and selegiline was loaded into nanospheres composed by poly(lactide-co-glycolide) [66]. These nanospheres were embedded into buccal films. In vivo evaluation was performed in rabbits to assess the comparative pharmacokinetics to buccal films and oral solution of drug. In-vivo results of film demonstrated significant increase in absorption ( $\mathrm{p}<0.0001)$, Cmax $(\sim 1.6-$ fold), Tmax $\mathrm{AUC}_{0-\infty}(\sim 3$-fold, $\mathrm{p}<0.0001)$ and improved bioavailability, when compared to drug in solution [66].

HPMC, Carbopol 940 and Eudragit ${ }^{\circledR}$ NE 40 D were used for preparation of films and these films were incorporated prednisolone for buccal delivery [67]. Pharmacokinetics profile was achieved and showed greater bioavailability $\left(\mathrm{AUC}_{0-\infty} 24.26 \pm 4.06 \mathrm{~g} \mathrm{~h} \mathrm{~mL}^{-1}\right.$ versus $\left.10.65 \pm 2.15 \mathrm{~g} \mathrm{~h} \mathrm{~mL}^{-1}\right)$ and higher $\mathrm{C}_{\max }\left(2.70 \pm 0.38 \mathrm{~g} \mathrm{~mL}^{-1}\right.$ versus $2.29 \pm 0.32 \mathrm{~g} \mathrm{~mL}^{-1}$ ) values when compared to oral suspension.

HPMC films were developed and loaded with rivastigmine and this formulation were administered in the mouth of rabbits [72]. Pharmacokinetics parameters were found and there results were $T_{\max }$ of $6 \mathrm{~h}$ and was found to be quite slow and sustained as compared with the marketed formulation ( $\mathrm{T}_{\max }$ of $0.75 \mathrm{~h}$ ) and a significant 1.7 -fold increase in the AUC compared to marketed formulation [72].

HPMC E5 LV and domperidone was formulated by hot-melt extrusion [68]. When administered, formulations had a in vivo residence time of $120 \mathrm{~min}$. Bioavailability was performed in healthy male volunteers and the values from the buccal film was 1.5 times higher than the oral dosage form and the results showed statistically significant $(p<0.05)$ difference [68].

Hydrophilic polymers either alone or in combination with bioadhesive polymers were used for film fabrication. Sodium carboxymethyl cellulose and hydroxypropyl cellulose were used for incorporation of diltiazem hydrochloride [69]. Studies in vivo were performed and a good correlation was observed between in vitro drug release and in vitro drug permeation with correlation coefficient ranged between of 0.945 to 0.980 . Bioavailability was assessed and compared to commercial sustained release oral tablet. AUC were higher for buccal administration (165.2\%) than oral administration and the difference was statistically significant $(\mathrm{p}<0.05)$ [69].

Carboxymethylcellulose and Carbopol 940P were used for manufacture of films by solvent casting method [70]. Films was designed for loading of salbutamol sulphate. Ratio of 76:24 (carboxymethylcellulose and Carbopol 940P) was found with moderate swelling and bioadhesion force properties. In vivo effect was evaluated and the bronchoprotection was determined for films administered via buccal route and may improve the treatment of asthmatic disorders. Moreover, reducing the frequency of administration of this drug which is associated with the tolerance effect.

Chitosan-ethylenediaminetetraacetic acid films for the mucoadhesive transbuccal delivery of insulin was developed [71]. Blood levels of glucose were determined for comparison of efficacy from buccal administration of films and subcutaneous administration of solution. Films administered at 5 and $14 \mathrm{UI} \mathrm{kg}^{-1}$ showed a decrease of glucose to 74 and $71 \%$, respectively. Pharmacological availability for buccal administration of the insulin-loaded films versus subcutaneous insulin injection reached $17 \%$ within $5 \mathrm{~h}$. No inflammation or changes of buccal tissue was found.

\subsection{Tablets}

Tablets are dosage forms and formed by hydrophilic matrix systems, in other words the polymers are compressed and can easily be prepared by direct compression of a powder mixture of drug with a release retardant, swollen polymer and other additives to aid processing [119]. Due to specific properties of the mucous layer on the buccal mucosa and mucoadhesive polymers from which the tablets are manufactured, tablets adhere to the mucosa [4]. The mechanism of drug release from hydrophilic matrices occurs when the polymer swells on contact with the aqueous medium to form a gel layer on the surface of the system $[120,121]$. Swelling of polymer permits a mechanical entanglement by exposing the bioadhesive sites for hydrogen bonding and/or electrostatic interaction between the polymer and the mucus network [122]. Diffusion, swelling and erosion of drugs are the most important ratecontrolling mechanisms of controlled release [123].

Matrix tablets offer numerous advantages in comparison to nonadhesive solid oral dosage forms as: (i) a close contact between the mucosa and the dosage form, (ii) a high drug concentration maintenance at the absorption surface for a prolonged period of time, (iii) the dosage form immobilization in a specific part of the oral mucosa, (iv) drug protection from the environment, (v) easy scale-up and and reproducibility of the manufacturing process [124].

Different types of mass transport processes can be involved in the control of the drug release from a dosage form $[125,126]$. In diffusioncontrolled release, a substance is released from a device by permeation 


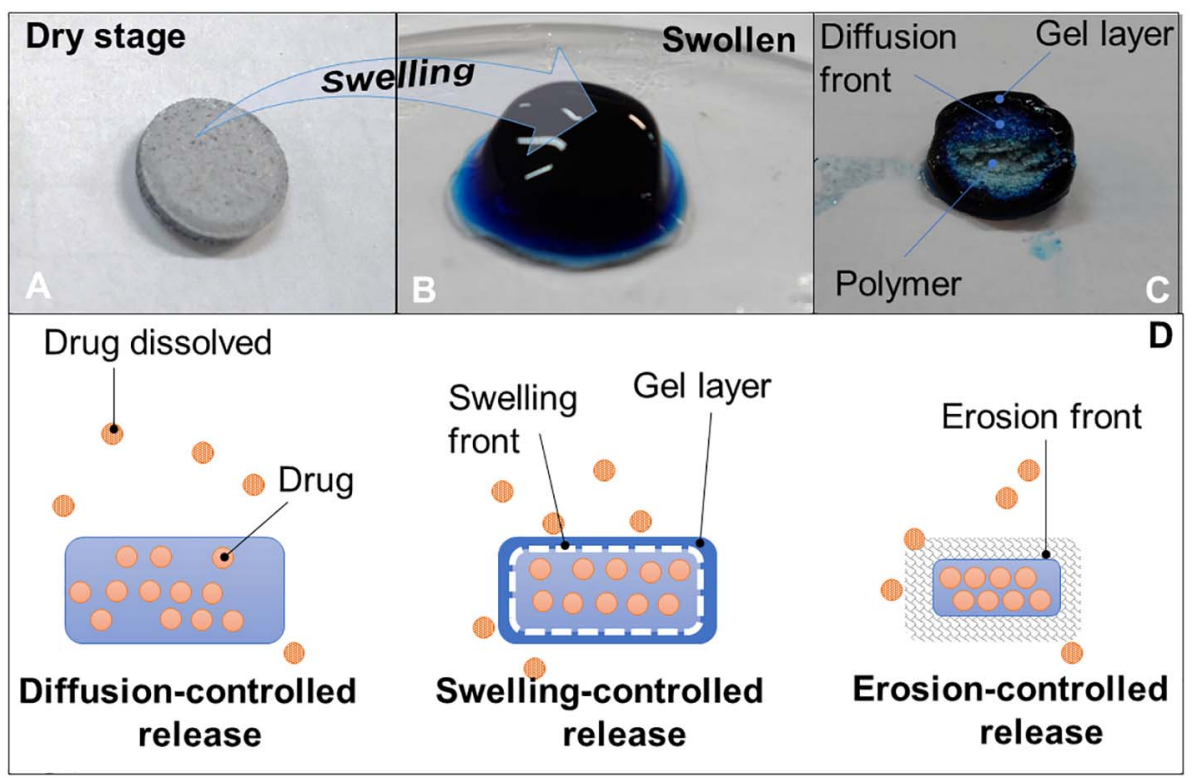

Fig. 7. Schematic photographs of swollen tablet ${ }^{\mathrm{a}}$. (A) Tablet in dry stage; (B) after swelling process, tablets is swollen; (C) cross-section of the swollen tablet showing the processes (gel layer and diffusion front) during a drug dissolution; (D) mechanisms of a drug release: diffusion, swelling, and erosion of a polymer matrix.

${ }^{\mathrm{a} C}$ Composed by $70 \%(\mathrm{~m} / \mathrm{m})$ of HPMC and $40 \%(\mathrm{~m} / \mathrm{m})$ of lactose. Methylene blue dye was incorporated at $1 \%(\mathrm{~m} / \mathrm{m})$ by weight of the tablet.

from its interior to the surrounding medium [127]. Polymer chains such as those in a cross-linked hydrogel form the diffusion barrier [125]. In some cases, drug diffusion is the predominant step and in others, it plays a major role in combination with polymer swelling or polymer degradation or both, or matrix erosion [128]. These mechanisms are shown in Fig. 7.

Swelling refers to the uptake of water by a polymer system with an increase in volume, and is often a prelude to polymer dissolution [129]. The swelling process is analogous to osmosis because water penetrates the polymer relatively rapidly. However, when the dissolution of the polymer in water occurs, it is comparatively slow because of the polymer chains need to detangle. The extent of swelling depends on the hydrophilicity of the polymeric materials and the density of the crosslinks between polymer chains [130].

Erosion-controlled systems have gained popularity with the development of biodegradable polymers and involve a chemical or physical polymer or material loss to control drug delivery [130]. The erosion process involves the loss of material owing to monomers and oligomers leaving the polymer. Polymer erosion is far more complex than degradation is because it depends on many other processes such as swelling, the dissolution and diffusion of oligomers and monomers, and morphological changes in the matrix [131]. Depending on the composition of an erodible device (e.g., the type of polymer, drug loading, and additives) and geometry (size and shape), numerous mass transport phenomena and chemical reactions affect the resulting drug release kinetics [132].

Meng-Lund et al. [73] prepareded co-spray-dried particles of chitosan and diazepam. Then, particles and excipients were direct compressed using a circular tablet punch with a diameter of $6 \mathrm{~mm}$. In vivo mini-pig study received the buccal tablet in the upper left or right buccal site of the cheek. Blood samples were collected, drug was determined in plasma, and then, pharmacokinetic parameters were calculated. Immediate release tablet intended for oral administration performed well, while the highest buccal bioavailability was seen for the mucoadhesive formulation, which could be due to an extended contact time. Absolute bioavailability (\%) for immediate release tablet administered to oral route was $30.5 \pm 6.1$ or by buccal route was $23.4 \pm 7.8$ and for tablets designed ranged to $19.6 \pm 8.8$ and $76.0 \pm 25.1$. The absorption rate for the chitosan-based tablets was significant slower, probably due to the slower diffusion of the drug by gel matrix tablet.

Tablets of ritodrine hydrochloride were prepared using the direct compression method with alginate, lactose, magnesium stearate, and microcrystalline cellulose as excipients [74]. Tablets were applied in the mucosa of rats and the pharmacokinetics were evaluated. AUC $\left(\mathrm{ng} \mathrm{mL} \mathrm{h}{ }^{-1}\right.$ ) was $137.4 \pm 15.7$ and $153.6 \pm 79.2$ for designed tablets and the absolute bioavailability (\%) was 3.3 and 3.7. The authors suggests of these tablets has possibly useful buccal tablets [74].

Omeprazole-loaded sodium alginate and HPMC tablets were obtained by direct compression method. The pharmacokinetic parameters were achieved in hamsters. The AUC values after intravenous and buccal administration were $10.09 \pm 3.74$ and $2.88 \pm 0.83 \mathrm{~h} \cdot \mu \mathrm{g} \mathrm{mL}^{-1}$, respectively. Thus, the absolute bioavailability of omeprazole was about $28.49 \%$ in hamsters. These buccal adhesive tablet has potential to buccal drug delivery [75].

Onishi et al. [76] designed ritodrine hydrochloride tablets containing alginate and lactose with or without microcrystalline cellulose as excipients. In vivo buccal absorption studies were performed in rats and the tablets was administered to the right cheek mucosa. Two formulations were tested, one has fairly fast release and other rapid dissolution. Analyses of the absorption rate and cumulative absorption amount confirmed that one showed rapid dissolution exhibited higher absorption rate for a prolonged period.

Kassem et al. [77] optimized tablets formulations varying the type of polymers and selected a formulation. This formulation was composed for cup as Carbopol 934P; HPMC K4M and ethyl cellulose and for core as sodium alginate. This formulation was able to adhere to the buccal mucosa for $8 \mathrm{~h}$. Pharmacokinetic study of selected tablets in human volunteers revealed a 5.6 fold increase in buspirone bioavailability compared to the oral commercial tablets [77].

Spray-dried microspheres were obtained mixture of carvedilol and chitosan. For design of tables, the core was made by spray-dried microspheres, Carbopol 934 P, lactose, talc and magnesium stearate; and the backing layer was made from ethyl cellulose and hydroxypropyl cellulose. Direct double-compression technique was employed for the formulation of bilayer mucoadhesive tablets consisting drug-loaded microspheres and excipients (ratio 1:4). Pharmacokinetics study was performed in rabbits and was administered orally conventional marketed tablet to compare the pharmacokinetic parameters after oral and buccal administrations. AUC ( $\mathrm{ng} \mathrm{mL} \mathrm{h}{ }^{-1}$ ) was $155.22 \pm 8.43$ and $390.75 \pm 5.23$ for oral administration and buccal administration, respectively. Thus, these results revealed almost 2.5 -fold increase in bioavailability of carvedilol after buccal administration of tablets formulation compared to conventional tablets after oral administration. Moreover, pharmacodynamics studies were performed in the hypertension-induced by fructose model. Pharmacodynamic studies 
showed significant reduction in the parameters such as mean arterial pressure and heart rate on administration of buccal bilayer tablet, confirming its suitability for the treatment of hypertension [78].

Shivanand et al. [79] designed Carbopol 934, HPMC K4M, HPMC $\mathrm{K} 15 \mathrm{M}$ along with ethyl cellulose as an impermeable backing layer were used for the preparation of mucoadhesive bilayered tablets. These systems were evaluated in vivo and bioavailability studies were conducted in rabbits for optimized formulation comparing to oral solution of sumatriptan succinate. Relative bioavailability of sumatriptan succinate from selected bilayered buccal tablets was achieved to $140.78 \%$ [79].

Felodipine and pioglitazone-loaded tablets were formulated with Carbopol 971P and HPMC K4M [80]. The bioavailability of optimized bioadhesive buccal tablet was compared with an oral suspension of drugs. $\mathrm{AUC}_{0-24}$ by the buccal route was 2.05- and 2.13-times higher than that of the oral route for felodipine and pioglitazone, respectively, and the difference was found to be statistically significant $(\mathrm{p}<0.05)$ [80].

Mucilage isolated from edible Dillenia indica fruits was used as excipient of tablets dosage forms [81]. Mucilage was granulated and then was compressed under the core tablets. Pharmacokinetics studies were performed in rabbits and the tablets designed exhibited $27.31 \%$ of bioavailability. At the end of in vivo experiment, the retrieved tablets were analyzed for oxytocin content. Only $41.26 \%$ oxytocin was present in the retrieved tablets. The remaining $31.43 \%$ oxytocin might be present in the buccal mucosa and may act as reservoir allowing slower diffusion to systemic circulation [81].

Chitosan and carbomer were used in the tablet formulations and the tablets were loaded with nicotine tartrate [82]. In vivo studies were performed non-smoker volunteers and a buccal tablet was applied on the buccal sulcus above the canine tooth and removed after $4 \mathrm{~h}$. Bioavailability of the tablet was evaluated in comparison to the transdermal patch. The Cmax values obtained with both delivery systems were found to be similar $(\mathrm{p}>0.05) . \quad \mathrm{AUC}_{0-12}$ values were $59.3 \pm 5.1 \mathrm{ng} \mathrm{h} \mathrm{mL}^{-1}$ and $204.1 \pm 31.2 \mathrm{ng} \mathrm{h} \mathrm{mL}^{-1}$ for buccal tablet and transdermal patch, respectively [82].

Sodium carboxymethyl cellulose tablets were loaded diltiazem hydrochloride and these matrix were evaluated in humans [133]. In all volunteers, the bioadhesive tablet remained in place for $>12 \mathrm{~h}$ without detachment, in addition, good correlation $(r=0.9398)$ was observed between in-vitro and in-vivo correlation [133].

Martín et al. [84] developed nystatin-loaded alginate microspheres coated-chitosan for oral mucosa drug delivery. In vivo studies were performed and were evaluated drug retention/permeation studies of buccal mucosa and histological studies in female pigs. Amounts of drug retained in the porcine mucosae were $3.79 \pm 1.13,4.73 \pm 0.18$ and $3.38 \pm 0.25 \mu \mathrm{g} / \mathrm{g}$ tissue $/ \mathrm{cm}^{2}$ for uncoated microspheres, chitosancoated microspheres and cross-linked microsphere, respectively and no amounts of nystatin were detected from the commercial suspension. The amount of drug in mucosa was between 4 and 6 times higher than the MIC value performed in Candida albicans. None histological changes were found and these systems preserve the mucosa microstructure [84].

Tablets based on chitosan microspheres containing chlorhexidine diacetate were developed and in vivo experiments were performed and placed on the buccal mucosa of volunteers [83]. At each time point samples of saliva were collected and the chlorhexidine concentration was determined by HPLC assay. The tablets were allowed for all the duration of the experiments of $4 \mathrm{~h}$. For two formulations tested, one after about 90 min partially disintegrates in the buccal cavity, while the second remained almost intact for about $3 \mathrm{~h}$. A concentration peak was determined within $30 \mathrm{~min}$ and $60 \mathrm{~min}$ for each formulation. The high capacity of tablets to give prolonged concentrations of drug in the buccal cavity could be due to the combination of chitosan with sodium alginate [83].

\section{Problems and challenges}

Mucosal membranes are moist surfaces lining on the walls of various body cavities such as respiratory, gastrointestinal, and reproductive tracts as well as the nostrils, the eyes, and the mouth. Mucus plays an important role in protecting the cellular epithelia from chemical and mechanical damage. The mucosal membranes also provide lubrication and wettability of the cell epithelial surface and regulate its moisture content [134]. The majority of the mucoadhesive drug delivery systems are formulated as tablets, solid inserts, wafers, films, gels, viscous solutions, particulate suspensions (micro and nanosize), in situ gelling systems, and sprays. In addition, these pharmaceutical systems and materials often incorporate polymeric excipients, which play a major role in their mucoadhesivity $[5,12,85,91]$. The mucoadhesive polymers not only increase the residence time at the site of administration, but also enhance the drug permeability through the epithelium by altering the tight junctions between the cells $[135,136]$.

The usefulness of the oral cavity as a site for the delivery of drugs locally or as a platform for the delivery of drugs into the systemic circulation has been associated with an ongoing effort over many decades, which, in recent years have seen the successful development of a variety of oral mucosal drug delivery systems $[18,137,138]$. The oral cavity is a challenging route for drug and it include permeability enhancement, dosage form retention at the site of application, and the continuous secretion of saliva and its subsequent swallowing, which can lead to substantial drug loss from the dosage form and hence low bioavailability [139].

To design optimal mucoadhesive therapeutic systems, it is necessary to know the characteristics of buccal site an of mucoadhesive properties of polymers. In this context, the search for improved mucoadhesive materials is a constant [140]. The future potential of buccal delivery systems looks favorable. It is envisaged that in the future, buccal and sublingual delivery technologies will provide a platform for the successful delivery of vaccines and antigens [138]. On the hand, many studies have developed products and evaluated them in vitro performance. Although, in vitro performance studies (dissolution and release/ permeation studies) may show feasible but not so true results from a biopharmaceutical point of view. Preclinical studies are much more sensitive to the performance evaluation of pharmaceutical products. Although these studies are conducted, but a small portion of the articles carried-out them. This can be understood, as perhaps, by the cost involved in R\&D at the academic level.

\section{Conclusion and remarks}

This review summarizes polymer-based drug delivery systems for buccal administration. In contrast, there are many studies that focus on the design and formulation of systems, but do not show the data of effectiveness and in vivo performance. Studies published in the literature, for the most part, are performed on rabbits and there is a minority that are carried out in humans. It is notable that for studies involving rabbits, dogs or pigs, as animal models, it is easier for administration the dosage forms on the buccal route. However, studies in rats and mice have also been reported.

Pharmacokinetic studies suggest a correlation pharmacokinetic/ pharmacodynamic of drugs. Many of these studies show that buccal bioavailability is comparable or equal to oral and intravascular routes. Thus, the oral route demonstrates an equity with the oral route, the most used, and with the intravenous route, an invasive route. Therefore, the use of these polymer-based drug delivery systems seems possible to control the release of drugs and increase their solubility or absorption, which subsequently increases or maintains pharmacodynamic and biological responses.

The use of these systems is increasing in the research and 
development of biomaterials and buccal delivery systems, but efficacy studies should be conducted to confirm the effect of drugs and these studies could be remarkable and will manifest themselves in new publications in the coming years.

\section{Author contributions}

BFS made substantial contributions to conceiving the idea for this review, searching the bibliographical data, conducting the analysis, and critically revising it for important intellectual content. MC conducted the analysis and revised the text critically for important intellectual content. Both coauthors approved the final version of the text for publication.

\section{Disclosure}

The authors report no conflicts of interest associated with this work.

\section{Acknowledgments}

The authors are grateful to the São Paulo Research Foundation-FAPESP (Grant number: 13/03746-3 and 15/05394-2) and for financial support.

\section{References}

[1] D. Harris, J.R. Robinson, Drug delivery via the mucous membranes of the oral cavity, J. Pharm. Sci. 81 (1992) 1-10.

[2] H.E. Junginger, J.A. Hoogstraate, J.C. Verhoef, Recent advances in buccal drug delivery and absorption - in vitro and in vivo studies, J. Control. Release 62 (1999) 149-159.

[3] A.H. Shojaei, Buccal mucosa as a route for systemic drug delivery: a review, J. Pharm. Pharm. Sci. 1 (1998) 15-30.

[4] N. Salamat-Miller, M. Chittchang, T.P. Johnston, The use of mucoadhesive polymers in buccal drug delivery, Adv. Drug Deliv. Rev. 57 (2005) 1666-1691.

[5] F. Laffleur, Mucoadhesive polymers for buccal drug delivery, Drug Dev. Ind. Pharm. 40 (2014) 591-598.

[6] K. Varaprasad, G.M. Raghavendra, T. Jayaramudu, M.M. Yallapu, R. Sadiku, A mini review on hydrogels classification and recent developments in miscellaneous applications, Mater. Sci. Eng. C 79 (2017) 958-971.

[7] W. Tsai, H. Tsai, Y. Wong, J. Hong, S. Chang, M. Lee, Preparation and characterization of gellan gum/glucosamine/clioquinol film as oral cancer treatment patch, Mater. Sci. Eng. C (2017), http://dx.doi.org/10.1016/j.msec.2017.05.040.

[8] M.I. Alvarez Echazú, C.E. Olivetti, C. Anesini, C.J. Perez, G.S. Alvarez, M.F. Desimone, Development and evaluation of thymol-chitosan hydrogels with antimicrobial-antioxidant activity for oral local delivery, Mater. Sci. Eng. C 81 (2017) 588-596.

[9] J. Kundu, C. Patra, S.C. Kundu, Design, fabrication and characterization of silk fibroin-HPMC-PEG blended films as vehicle for transmucosal delivery, Mater. Sci. Eng. C 28 (2008) 1376-1380.

[10] N.A. Peppas, J.J. Sahlin, Hydrogels as mucoadhesive and bioadhesive materials: a review, Biomaterials 17 (1996) 1553-1561.

[11] J.W. Lee, J.H. Park, J.R. Robinson, Bioadhesive-based dosage forms: the next generation, J. Pharm. Sci. 89 (2000) 850-866.

[12] M.L. Bruschi, O. de Freitas, Oral bioadhesive drug delivery systems, Drug Dev. Ind. Pharm. 31 (2005) 293-310.

[13] P.O. Glantz, T. Arnebrant, T. Nylander, R.E. Baier, Bioadhesion-a phenomenon with multiple dimensions, Acta Odontol. Scand. 57 (1999) 238-241.

[14] Y. Huang, W. Leobandung, A. Foss, N.A. Peppas, Molecular aspects of muco- and bioadhesion, J. Control. Release 65 (2000) 63-71.

[15] A. Ahuja, R.K. Khar, J. Ali, Mucoadhesive drug delivery systems, Drug Dev. Ind. Pharm. 23 (1997) 489-515.

[16] K.K. Peh, C.F. Wong, Polymeric films as vehicle for buccal delivery: swelling, mechanical, and bioadhesive properties, J. Pharm. Pharm. Sci. 2 (1999) 53-61.

[17] J.D. Smart, Buccal drug delivery, Expert Opin. Drug Deliv. 2 (2005) 507-517.

[18] V.F. Patel, F. Liu, M.B. Brown, Advances in oral transmucosal drug delivery, J. Control. Release 153 (2011) 106-116.

[19] M. Sattar, O.M. Sayed, M.E. Lane, Oral transmucosal drug delivery-current status and future prospects, Int. J. Pharm. 471 (2014) 498-506.

[20] J. Hao, P.W. Heng, Buccal delivery systems, Drug Dev. Ind. Pharm. 29 (2003) 821-832.

[21] J.D. Smart, Recent developments in the use of bioadhesive systems for delivery of drugs to the oral cavity, Crit. Rev. Ther. Drug Carrier Syst. 21 (2004) 319-344.

[22] H. Kraan, H. Vrieling, C. Czerkinsky, W. Jiskoot, G. Kersten, J.-P. Amorij, Buccal and sublingual vaccine delivery, J. Control. Release 190 (2014) 580-592.

[23] L.M. Collins, C. Dawes, The surface area of the adult human mouth and thickness of the salivary film covering the teeth and oral mucosa, J. Dent. Res. 66 (1987) $1300-1302$.
[24] R.B. Gandhi, J.R. Robinson, Oral cavity as a site for bioadhesive drug delivery, Adv. Drug Deliv. Rev. 13 (1994) 43-74.

[25] S.J. Farnaud, O. Kosti, S.J. Getting, D. Renshaw, Saliva: physiology and diagnostic potential in health and disease, TheScientificWorldJOURNAL 10 (2010) 434-456.

[26] S.D. Bradway, E.J. Bergey, P.C. Jones, M.J. Levine, Oral mucosal pellicle. Adsorption and transpeptidation of salivary components to buccal epithelial cells, Biochem. J. 261 (1989) 887-896.

[27] L.A. Tabak, M.J. Levine, I.D. Mandel, S.A. Ellison, Role of salivary mucins in the protection of the oral cavity, J. Oral Pathol. 11 (1982) 1-17.

[28] B.L. Slomiany, V.L. Murty, J. Piotrowski, A. Slomiany, Salivary mucins in oral mucosal defense, Gen. Pharmacol. 27 (1996) 761-771.

[29] R. Bansil, E. Stanley, J.T. LaMont, Mucin biophysics, Annu. Rev. Physiol. 57 (1995) 635-657.

[30] F.-G. Hanisch, S. Müller, MUC1: the polymorphic appearance of a human mucin, Glycobiology 10 (2000) 439-449.

[31] C. Paderni, D. Compilato, L.I. Giannola, G. Campisi, Oral local drug delivery and new perspectives in oral drug formulation, Oral Surg. Oral Med. Oral Pathol. Oral Radiol. 114 (2012) e25-e34.

[32] S. Şenel, A.A. Hıncal, Drug permeation enhancement via buccal route: possibilities and limitations, J. Control. Release 72 (2001) 133-144.

[33] P. Shakya, N.V.S. Madhav, A.K. Shakya, K. Singh, Palatal mucosa as a route for systemic drug delivery: a review, J. Control. Release 151 (2011) 2-9.

[34] N.V.S. Madhav, A.K. Shakya, P. Shakya, K. Singh, Orotransmucosal drug delivery systems: a review, J. Control. Release 140 (2009) 2-11.

[35] T.K. Ghosh, W.R. Pfister, Drug Delivery to the Oral Cavity: Molecules to Market, CRC Press, Boca Raton, 2005.

[36] F. Veuillez, Y.N. Kalia, Y. Jacques, J. Deshusses, P. Buri, Factors and strategies for improving buccal absorption of peptides, Eur. J. Pharm. Biopharm. 51 (2001) 93-109.

[37] R.C.C. Silva, D.R. Campos, P. De Oliveira, A.G.V. Laguna, V. De Souza Magalhães, Y.P. Cid, M.B. De Almeida, F.B. Scott, J.I. Fernandes, Effcacy of chitosan gel mucoadhesive containing doxycycline associated or not to meloxicam as adjuvant to treatment of gingivitis in dogs with periodontal disease, Rev. Bras. Med. Vet. 38 (2016) 40-44.

[38] D.L. Harris, P.J. Weston, M. Signal, J.G. Chase, J.E. Harding, Dextrose gel for neonatal hypoglycaemia (the Sugar Babies Study): a randomised, double-blind, placebo-controlled trial, Lancet 382 (2013) 2077-2083.

[39] L. Jin, B.J. Boyd, I.C. Larson, M.W. Pennington, R.S. Norton, J.A. Nicolazzo, Enabling noninvasive systemic delivery of the Kv1.3-blocking peptide HsTX1[R14A] via the buccal mucosa, J. Pharm. Sci. 105 (2016) 2173-2179.

[40] H.A. Hazzah, R.M. Farid, M.M.A. Nasra, M. Zakaria, Y. Gawish, M.A. El-Massik, O.Y. Abdallah, A new approach for treatment of precancerous lesions with curcumin solid-lipid nanoparticle-loaded gels: in vitro and clinical evaluation, Drug Deliv. 23 (2016) 1409-1419.

[41] M. Singh, J. Kanoujia, P. Singh, P. Parashar, M. Arya, C.B. Tripathi, V.R. Sinha, S.A. Saraf, Development of an [small alpha]-linolenic acid containing a soft nanocarrier for oral delivery-part II: buccoadhesive gel, RSC Adv. 6 (2016) 101602-101612.

[42] T.B. Graciano, T.S. Coutinho, C.B. Cressoni, C.d.P. Freitas, M.B.R. Pierre, S.A. de Lima Pereira, M.M. Shimano, R. Cristina da Cunha Frange, M.T.J. Garcia, Using chitosan gels as a toluidine blue $\mathrm{O}$ delivery system for photodynamic therapy of buccal cancer: in vitro and in vivo studies, Photodiagn. Photodyn. Ther. 12 (2015) 98-107

[43] L. Jin, B.J. Boyd, P.J. White, M.W. Pennington, R.S. Norton, J.A. Nicolazzo, Bucca mucosal delivery of a potent peptide leads to therapeutically-relevant plasma concentrations for the treatment of autoimmune diseases, J. Control. Release 199 (2015) 37-44.

[44] J. Xu, S. Strandman, J.X.X. Zhu, J. Barralet, M. Cerruti, Genipin-crosslinked catechol-chitosan mucoadhesive hydrogels for buccal drug delivery, Biomaterials 37 (2015) 395-404.

[45] D. Neha, K. Krishan, A.N. Kalia, A. Saahil, N-succinyl chitosan as buccal penetration enhancer for delivery of herbal agents in treatment of oral mucositis, Curr. Drug Deliv. 11 (2014) 415-425.

[46] P.P. Nerkar, S.G. Gattani, Oromucosal delivery of venlafaxine by linseed mucilage based gel: in vitro and in vivo evaluation in rabbits, Arch. Pharm. Res. 36 (2013) $846-853$

[47] S.G. Choi, E.J. Baek, E. Davaa, Y.-C. Nho, Y.-M. Lim, J.-S. Park, H.-J. Gwon, K.M. Huh, J.-S. Park, Topical treatment of the buccal mucosa and wounded skin in rats with a triamcinolone acetonide-loaded hydrogel prepared using an electron beam, Int. J. Pharm. 447 (2013) 102-108.

[48] O.M. Sayed, A.A. Ali, M.A. El-Nabarawi, A.A. Bary, Bioequivalence study of bucca formulations of two prokinetic agents versus the conventional oral tablets, Int. J. Drug Deliv. 5 (2013) 257-263.

[49] M.H. Elkomy, S.F. El Menshawe, H.A. Abou-Taleb, M.H. Elkarmalawy, Loratadine bioavailability via buccal transferosomal gel: formulation, statistical optimization, in vitro/in vivo characterization, and pharmacokinetics in human volunteers, Drug Deliv. 24 (2017) 781-791.

[50] S.Y. Karavana, E.H. Gökçe, S. Rençber, S. Özbal, Ç. Pekçetin, P. Güneri, G. Ertan, A new approach to the treatment of recurrent aphthous stomatitis with bioadhesive gels containing cyclosporine A solid lipid nanoparticles: in vivo/in vitro examinations, Int. J. Nanomedicine 7 (2012) 5693-5704.

[51] P.P. Nerkar, S.G. Gattani, Cress seed mucilage based buccal mucoadhesive gel of venlafaxine: in vivo, in vitro evaluation, J. Mater. Sci. Mater. Med. 23 (2012) 771-779.

[52] U. Krotscheck, D.M. Boothe, A.A. Little, H.N. Erb, Pharmacokinetics of buprenorphine in a sodium carboxymethylcellulose gel after buccal transmucosal 
administration in dogs, Vet. Ther. 11 (2010).

[53] A.K. Philip, M. Srivastava, K. Pathak, Buccoadhesive gels of glibenclamide: a means for achieving enhanced bioavailability, Drug Deliv. 16 (2009) 405-415.

[54] R. Pignatello, L. Basile, G. Puglisi, Chitosan glutamate hydrogels with local anesthetic activity for buccal application, Drug Deliv. 16 (2009) 176-181.

[55] M.K. Dhiman, A. Dhiman, K.K. Sawant, Transbuccal delivery of 5-fluorouracil: permeation enhancement and pharmacokinetic study, AAPS PharmSciTech 10 (2009) 258-265.

[56] G.T. Reddy, T.M.P. Kumar, K.M. Veena, Formulation and evaluation of alendronate sodium gel for the treatment of bone resorptive lesions in periodontitis, Drug Deliv. 12 (2005) 217-222.

[57] S.-C. Shin, J.-P. Bum, J.-S. Choi, Enhanced bioavailability by buccal administration of triamcinolone acetonide from the bioadhesive gels in rabbits, Int. J. Pharm. 209 (2000) 37-43.

[58] M. Kitano, Y. Maitani, K. Takayama, T. Nagai, Buccal absorption through golden hamster cheek pouch in vitro and in vivo of $17 \beta$-estradiol from hydrogels containing three types of absorption enhancers, Int. J. Pharm. 174 (1998) 19-28.

[59] R. Kamel, A. Mahmoud, G. El-Feky, Double-phase hydrogel for buccal delivery of tramadol, Drug Dev. Ind. Pharm. 38 (2012) 468-483.

[60] Z. Daněk, J. Gajdziok, P. Doležel, H. Landová, D. Vetchý, J. Štembírek, Buccal films as a dressing for the treatment of aphthous lesions, J. Oral Pathol. Med. 46 (2017) 301-306.

[61] P. Rana, R.S.R. Murthy, Formulation and evaluation of mucoadhesive buccal films impregnated with carvedilol nanosuspension: a potential approach for delivery of drugs having high first-pass metabolism, Drug Deliv. 20 (2013) 224-235.

[62] D.-M. Park, Y.-K. Song, J.-P. Jee, H.T. Kim, C.-K. Kim, Development of chitosanbased ondansetron buccal delivery system for the treatment of emesis, Drug Dev. Ind. Pharm. 38 (2012) 1077-1083.

[63] Z. Cui, R.J. Mumper, Buccal transmucosal delivery of calcitonin in rabbits using thin-film composites, Pharm. Res. 19 (2002) 1901-1906.

[64] S.A. Mohamad, H.A. Sarhan, H. Abdelkader, H.F. Mansour, Vitamin B12-loaded buccoadhesive films as a noninvasive supplement in vitamin B12 deficiency: in vitro evaluation and in vivo comparative study with intramuscular injection, $\mathrm{J}$. Pharm. Sci. 106 (2017) 1849-1858.

[65] R.I. Reda, M.M. Wen, A.H. El-Kamel, Ketoprofen-loaded Eudragit electrospun nanofibers for the treatment of oral mucositis, Int. J. Nanomedicine 12 (2017) 2335-2351.

[66] B.E. Al-Dhubiab, A.B. Nair, R. Kumria, M. Attimarad, S. Harsha, Development and evaluation of buccal films impregnated with selegiline-loaded nanospheres, Drug Deliv. 23 (2016) 2154-2162.

[67] R. Kumria, A.B. Nair, G. Goomber, S. Gupta, Buccal films of prednisolone with enhanced bioavailability, Drug Deliv. 23 (2016) 471-478.

[68] C.R. Palem, S. Kumar Battu, S. Maddineni, R. Gannu, M.A. Repka, M.R. Yamsani, Oral transmucosal delivery of domperidone from immediate release films produced via hot-melt extrusion technology, Pharm. Dev. Technol. 18 (2013) $186-195$.

[69] M.I. Mohamed, M. Haider, M.A.M. Ali, Buccal mucoadhesive films containing antihypertensive drug: in vitro/in vivo evaluation, J. Chem. Pharm. Res. 3 (2011) 665-686.

[70] S. Singh, R. Soni, M.K. Rawat, A. Jain, S.B. Deshpande, S.K. Singh, M.S. Muthu, In vitro and in vivo evaluation of buccal bioadhesive films containing salbutamol sulphate, Chem. Pharm. Bull. 58 (2010) 307-311.

[71] F. Cui, C. He, M. He, C. Tang, L. Yin, F. Qian, C. Yin, Preparation and evaluation of chitosan-ethylenediaminetetraacetic acid hydrogel films for the mucoadhesive transbuccal delivery of insulin, J. Biomed. Mater. Res. A 89 (2009) 1063-1071.

[72] R. Kapil, S. Dhawan, S. Beg, B. Singh, Buccoadhesive films for once-a-day administration of rivastigmine: systematic formulation development and pharmacokinetic evaluation, Drug Dev. Ind. Pharm. 39 (2013) 466-480.

[73] E. Meng-Lund, J. Jacobsen, A. Müllertz, E.B. Jørgensen, R. Holm, Buccal absorption of diazepam is improved when administered in bioadhesive tablets-an in vivo study in conscious Göttingen mini-pigs, Int. J. Pharm. 515 (2016) 125-131.

[74] H. Onishi, O. Sakata, K. Yumoto, In vitro and in vivo evaluations of buccal tablet formulations of ritodrine hydrochloride, Biol. Pharm. Bull. 38 (2015) 919-925.

[75] K.H. Cho, A.M. Yousaf, D.W. Kim, F.U. Din, P.S. Chang, H.H. Baek, H.G. Choi, E. Oh, Effect of sodium taurocholate on omeprazole buccal adhesive tablet: physicochemical characterization and pharmacokinetics in hamster, Curr. Pharm. Anal. 11 (2015) 98-103.

[76] H. Onishi, K. Yumoto, O. Sakata, Preparation and evaluation of ritodrine buccal tablets for rational therapeutic use, Int. J. Pharm. 468 (2014) 207-213.

[77] M.A.A. Kassem, A.N. ElMeshad, A.R. Fares, Enhanced bioavailability of buspirone hydrochloride via cup and core buccal tablets: formulation and in vitro/in vivo evaluation, Int. J. Pharm. 463 (2014) 68-80.

[78] P. Yedurkar, M.K. Dhiman, K. Petkar, K. Sawant, Mucoadhesive bilayer buccal tablet of carvedilol-loaded chitosan microspheres: in vitro, pharmacokinetic and pharmacodynamic investigations, J. Microencapsul. 29 (2012) 126-137.

[79] K. Shivanand, S.A. Raju, S. Nizamuddin, B. Jayakar, In vivo bioavailability studies of sumatriptan succinate buccal tablets, DARU, J. Pharm. Sci. 19 (2011) 224-230.

[80] C.R. Palem, R. Gannu, S.K. Yamsani, V.V. Yamsani, M.R. Yamsani, Development of bioadhesive buccal tablets for felodipine and pioglitazone in combined dosage form: in vitro, ex vivo, and in vivo characterization, Drug Deliv. 18 (2011) 344-352.

[81] P.K. Metia, A.K. Bandyopadhyay, In vitro and in vivo evaluation of a novel mucoadhesive buccal oxytocin tablet prepared with Dillenia indica fruit mucilage, Pharmazie 63 (2008) 270-274.

[82] G. Ikinci, S. Şenel, L. Tokgözoğlu, C.G. Wilson, M. Şumnu, Development and in vitro/in vivo evaluations of bioadhesive buccal tablets for nicotine replacement therapy, Pharmazie 61 (2006) 203-207.

[83] P. Giunchedi, C. Juliano, E. Gavini, M. Cossu, M. Sorrenti, Formulation and in vivo evaluation of chlorhexidine buccal tablets prepared using drug-loaded chitosan microspheres, Eur. J. Pharm. Biopharm. 53 (2002) 233-239.

[84] M.J. Martín, A.C. Calpena, F. Fernández, M. Mallandrich, P. Gálvez, B. Clares, Development of alginate microspheres as nystatin carriers for oral mucosa drug delivery, Carbohydr. Polym. 117 (2015) 140-149.

[85] J.D. Smart, The basics and underlying mechanisms of mucoadhesion, Adv. Drug Deliv. Rev. 57 (2005) 1556-1568.

[86] S.-H.S. Leung, J.R. Robinson, Polymer structure features contributing to mucoadhesion. II, J. Control. Release 12 (1990) 187-194.

[87] F.C. Carvalho, M. Chorilli, M.P.D. Gremião, Plataformas bio(muco) adesivas poliméricas baseadas em nanotecnologia para liberação controlada de fármacos propriedades, metodologias e aplicações, Polímeros 24 (2014) 203-213.

[88] H. Hagerstrom, K. Edsman, M. Stromme, Low-frequency dielectric spectroscopy as a tool for studying the compatibility between pharmaceutical gels and mucous tissue, J. Pharm. Sci. 92 (2003) 1869-1881.

[89] E. Mathiowitz, D.E. Chickering, C.M. Lehr, Bioadhesive Drug Delivery Systems: Fundamentals, Novel Approaches, and Development, Marcel Dekker, New York, 1999.

[90] V.V. Khutoryanskiy, Advances in mucoadhesion and mucoadhesive polymers, Macromol. Biosci. 11 (2011) 748-764.

[91] J.D. Smart, Theories of mucoadhesion, Mucoadhesive Materials and Drug Delivery Systems, John Wiley \& Sons, Ltd, 2014, pp. 159-174.

[92] N.A. Peppas, P. Bures, W. Leobandung, H. Ichikawa, Hydrogels in pharmaceutical formulations, Eur. J. Pharm. Biopharm. 50 (2000) 27-46.

[93] J. Jagur-Grodzinski, Polymeric gels and hydrogels for biomedical and pharmaceutical applications, Polym. Adv. Technol. 21 (2010) 27-47.

[94] S.S. Liow, Q. Dou, D. Kai, Z. Li, S. Sugiarto, C.Y.Y. Yu, R.T.K. Kwok, X. Chen, Y. L. Wu, S.T. Ong, A. Kizhakeyil, N.K. Verma, B.Z. Tang, X.J. Loh, Long-term realtime in vivo drug release monitoring with AIE thermogelling polymer, Small 13 (2017) (1603404-n/a)

[95] J. Li, D.J. Mooney, Designing Hydrogels for Controlled Drug Delivery, 1 (2016), p. 16071.

[96] X.J. Loh, O.A. Scherman, Polymeric and Self Assembled Hydrogels: From Fundamental Understanding to Applications, The Royal Society of Chemistry, Cambridge, 2013.

[97] B. Choi, X.J. Loh, A. Tan, C.K. Loh, E. Ye, M.K. Joo, B. Jeong, Introduction to in situ forming hydrogels for biomedical applications, in: X.J. Loh (Ed.), In-Situ Gelling Polymers for Biomedical Applications, Springer, Singapore, 2015.

[98] C. He, S.W. Kim, D.S. Lee, In situ gelling stimuli-sensitive block copolymer hydrogels for drug delivery, J. Control. Release 127 (2008) 189-207.

[99] S.R. Van Tomme, G. Storm, W.E. Hennink, In situ gelling hydrogels for pharmaceutical and biomedical applications, Int. J. Pharm. 355 (2008) 1-18.

[100] M. Prabaharan, J.F. Mano, Stimuli-responsive hydrogels based on polysaccharide incorporated with thermo-responsive polymers as novel biomaterials, Macromol. Biosci. 6 (2006) 991-1008.

[101] Q.Q. Dou, S.S. Liow, E. Ye, R. Lakshminarayanan, X.J. Loh, Biodegradable thermogelling polymers: working towards clinical applications, Adv. Healthc. Mater. 3 (2014) 977-988.

[102] G. Barouti, S.S. Liow, Q. Dou, H. Ye, C. Orione, S.M. Guillaume, X.J. Loh, New linear and star-shaped thermogelling poly([R]-3-hydroxybutyrate) copolymers, Chem. Eur. J. 22 (2016) 10501-10512.

[103] Ajazuddin, A. Alexander, J. Khan, T.K. Giri, D.K. Tripathi, S. Saraf, S. Saraf, Advancement in stimuli triggered in situ gelling delivery for local and systemic route, Expert Opin. Drug Deliv. 9 (2012) 1573-1592.

[104] X.J. Loh, J. Li, Biodegradable thermosensitive copolymer hydrogels for drug delivery, Expert Opin. Ther. Pat. 17 (2007) 965-977.

[105] N.A. Peppas, Physiologically responsive hydrogels, J. Bioact. Compat. Polym. 6 (1991) 241-246.

[106] T.R. Hoare, D.S. Kohane, Hydrogels in drug delivery: progress and challenges, Polymer 49 (2008) 1993-2007.

[107] D. Kai, S.S. Liow, X.J. Loh, Biodegradable polymers for electrospinning: towards biomedical applications, Mater. Sci. Eng. C 45 (2014) 659-670.

[108] H. Ye, C. Owh, S. Jiang, C. Ng, D. Wirawan, X. Loh, A. Thixotropic Polyglycerol, Sebacate-based supramolecular hydrogel as an injectable drug delivery matrix, Polymer 8 (2016) 130

[109] R.M. Gilhotra, M. Ikram, S. Srivastava, N. Gilhotra, A clinical perspective on mucoadhesive buccal drug delivery systems, J. Biomed. Res. 28 (2014) 81-97.

[110] M. Cornblath, J.M. Hawdon, A.F. Williams, A. Aynsley-Green, M.P. Ward-Platt, R. Schwartz, S.C. Kalhan, Controversies regarding definition of neonatal hypoglycemia: suggested operational thresholds, Pediatrics 105 (2000) 1141-1145.

[111] P.J. Weston, D.L. Harris, M. Battin, J. Brown, J.E. Hegarty, J.E. Harding, Oral dextrose gel for the treatment of hypoglycaemia in newborn infants, Cochrane Database Syst. Rev. (2016), http://dx.doi.org/10.1002/14651858.CD011027. pub2.

[112] M.R. Tanner, R.B. Tajhya, R. Huq, E.J. Gehrmann, K.E. Rodarte, M.A. Atik, R.S. Norton, M.W. Pennington, C. Beeton, Prolonged immunomodulation in inflammatory arthritis using the selective Kv1.3 channel blocker HsTX1[R14A] and its PEGylated analog, Clin. Immunol. 180 (2017) 45-57.

[113] Jitendra, P.K. Sharma, S. Bansal, A. Banik, Noninvasive routes of proteins and peptides drug delivery, Indian J. Pharm. Sci. 73 (2011) 367-375.

[114] T. Caon, L. Jin, C.M.O. Simões, R.S. Norton, J.A. Nicolazzo, Enhancing the buccal mucosal delivery of peptide and protein therapeutics, Pharm. Res. 32 (2015) 1-21.

[115] W. Lonette, K. Elmarie, D.T. Trizel, G. Chrisna, S. Dewald, S. Jan, V. Joe, H. Josias, Novel non-invasive protein and peptide drug delivery approaches, Protein Pept. 
Lett. 21 (2014) 1087-1101.

[116] B.J. Bruno, G.D. Miller, C.S. Lim, Basics and recent advances in peptide and protein drug delivery, Ther. Deliv. 4 (2013) 1443-1467.

[117] M.A. Attia, I. El-Gibaly, S.E. Shaltout, G.N. Fetih, Transbuccal permeation, antiinflammatory activity and clinical efficacy of piroxicam formulated in different gels, Int. J. Pharm. 276 (2004) 11-28.

[118] R.R. Sravanthi, R. Rajalakshmi, S.B. Krishna Moorthy, V. Rupangada, E. Ramya Sudha, Mucoadhesive buccal films: an innovative drug delivery system, Int. J. PharmTech Res. 6 (2014) 1665-1678.

[119] M.U. Ghori, B.R. Conway, Hydrophilic matrices for oral control drug delivery, Am. J. Pharmacol. Sci. 3 (2015) 103-109.

[120] L. Perioli, C. Pagano, Preformulation studies of mucoadhesive tablets for carbamazepine sublingual administration, Colloids Surf. B: Biointerfaces 102 (2013) 915-922.

[121] Y. Ikeuchi-Takahashi, M. Sasatsu, H. Onishi, Evaluation of matrix type mucoadhesive tablets containing indomethacin for buccal application, Int. J. Pharm. 453 (2013) 454-461.

[122] J.M. Gu, J.R. Robinson, S.H. Leung, Binding of acrylic polymers to mucin/epithelial surfaces: structure-property relationships, Crit. Rev. Ther. Drug Carrier Syst. 5 (1988) 21-67.

[123] R. Langer, N. Peppas, Chemical and physical structure of polymers as carriers for controlled release of bioactive agents: a review, J. Macromol. Sci. C 23 (1983) 61-126.

[124] Y. Sudhakar, K. Kuotsu, A.K. Bandyopadhyay, Buccal bioadhesive drug delivery a promising option for orally less efficient drugs, J. Control. Release 114 (2006) $15-40$.

[125] K.E. Uhrich, S.M. Cannizzaro, R.S. Langer, K.M. Shakesheff, Polymeric systems for controlled drug release, Chem. Rev. 99 (1999) 3181-3198.

[126] B. Narasimhan, N.A. Peppas, Molecular analysis of drug delivery systems controlled by dissolution of the polymer carrier, J. Pharm. Sci. 86 (1997) 297-304.

[127] X. Huang, C.S. Brazel, On the importance and mechanisms of burst release in matrix-controlled drug delivery systems, J. Control. Release 73 (2001) 121-136.
[128] J. Siepmann, F. Siepmann, Modeling of diffusion controlled drug delivery, J. Control. Release 161 (2012) 351-362.

[129] R.S. Harland, A. Gazzaniga, M.E. Sangalli, P. Colombo, N.A. Peppas, Drug/ polymer matrix swelling and dissolution, Pharm. Res. 5 (1988) 488-494.

[130] R.A. Siegel, M.J. Rathbone, Overview of controlled release mechanisms, in: J. Siepmann, R.A. Siegel, M.J. Rathbone (Eds.), Fundamentals and Applications of Controlled Release Drug Delivery, Springer, New York, 2012, pp. 19-43.

[131] A. Göpferich, Mechanisms of polymer degradation and erosion, Biomaterials 17 (1996) 103-114.

[132] J. Siepmann, A. Göpferich, Mathematical modeling of bioerodible, polymeric drug delivery systems, Adv. Drug Deliv. Rev. 48 (2001) 229-247.

[133] N.A. Nafee, F.A. Ismail, N.A. Boraie, L.M. Mortada, Mucoadhesive delivery systems. II. Formulation and in-vitro/in-vivo evaluation of buccal mucoadhesive tablets containing water-soluble drugs, Drug Dev. Ind. Pharm. 30 (2004) 995-1004.

[134] R.A. Cone, Barrier properties of mucus, Adv. Drug Deliv. Rev. 61 (2009) 75-85.

[135] G. Sandri, S. Rossi, F. Ferrari, M.C. Bonferoni, N. Zerrouk, C. Caramella, Mucoadhesive and penetration enhancement properties of three grades of hyaluronic acid using porcine buccal and vaginal tissue, Caco-2 cell lines, and rat jejunum, J. Pharm. Pharmacol. 56 (2004) 1083-1090.

[136] G. Sandri, S. Rossi, F. Ferrari, M.C. Bonferoni, C. Muzzarelli, C. Caramella, Assessment of chitosan derivatives as buccal and vaginal penetration enhancers, Eur. J. Pharm. Sci. 21 (2004) 351-359.

[137] S.I. Pather, M.J. Rathbone, S. Senel, Current status and the future of buccal drug delivery systems, Expert Opin. Drug Deliv. 5 (2008) 531-542.

[138] S. Senel, M.J. Rathbone, M. Cansiz, I. Pather, Recent developments in buccal and sublingual delivery systems, Expert Opin. Drug Deliv. 9 (2012) 615-628.

[139] I.W. Kellaway, G.P.a.D. Duchêne, Oral mucosal drug delivery, in: M.J. Rathbone, J. Hadgraft, M.S. Roberts (Eds.), Modified-release Drug Delivery Technology, Marcel Dekker, Nre York, 2002, pp. 349-364.

[140] M.L. Bruschi, L.M.B.d. Francisco, L.d.A.S.d. Toledo, F.B. Borghi, An overview of recent patents on composition of mucoadhesive drug delivery systems, Recent Pat. Drug Deliv. Formul. 9 (2015) 79-87. 